\title{
Vascular Tissue Contractility Changes Following Late Gestational Exposure to Multi-Walled Carbon Nanotubes or their Dispersing Vehicle in Sprague Dawley Rats
}

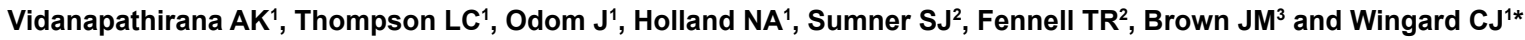 \\ ${ }^{1}$ Department of Physiology, Brody School of Medicine, East Carolina University, NC 27834, USA \\ ${ }^{2}$ Discovery Sciences, RTI International, Research Triangle Park, NC, 27709, USA \\ ${ }^{3}$ Department of Pharmaceutical Sciences, Skaggs School of Pharmacy and Pharmaceutical Sciences, University of Colorado, CO, 80045, USA
}

\begin{abstract}
Multi-walled carbon nanotubes (MWCNTs) are increasingly used in industry and in nanomedicine raising safety concerns, especially during unique life-stages such as pregnancy. We hypothesized that MWCNT exposure during pregnancy will increase vascular tissue contractile responses by increasing Rho kinase signaling. Pregnant (17-19 gestational days) and non-pregnant Sprague Dawley rats were exposed to $100 \mu \mathrm{g} / \mathrm{kg}$ of MWCNTs by intratracheal instillation or intravenous administration. Vasoactive responses of uterine, mesenteric, aortic and umbilical vessels were studied 24 hours post-exposure by wire myography. The contractile responses of the vessel segments were different between the pregnant and non-pregnant rats, following MWCNT exposure. Maximum stress generation in the uterine artery segments from the pregnant rats following pulmonary MWCNT exposure was increased in response to angiotensin II by $4.9 \mathrm{mN} / \mathrm{mm}^{2}(+118 \%)$, as compared to the naïve response and by $2.6 \mathrm{mN} / \mathrm{mm}^{2}(+40.7 \%)$ as compared to the vehicle exposed group. Following MWCNT exposure, serotonin induced approximately $4 \mathrm{mN} / \mathrm{mm}^{2}$ increase in stress generation of the mesenteric artery from both pregnant and non-pregnant rats as compared to the vehicle response. A significant contribution of the dispersion medium was identified as inducing changes in the contractile properties following both pulmonary and intravenous exposure to MWCNTs. Wire myographic studies in the presence of a Rho kinase inhibitor and RhoA and Rho kinase mRNA/protein expression of rat aortic endothelial cells were unaltered following exposure to MWCNTs, suggesting absent/minimal contribution of Rho kinase to the enhanced contractile responses following MWCNT exposure. The reactivity of the umbilical vein was not changed; however, mean fetal weight gain was reduced with dispersion media and MWCNT exposure by both routes. These results suggest a susceptibility of the vasculature during gestation to MWCNT and their dispersion media-induced vasoconstriction, predisposing reduced fetal growth during pregnancy.
\end{abstract}

Keywords: Vascular tissue contractility; Pregnancy; Uterine artery; Umbilical vein; Nanotoxicology; MWCNTs

Abbreviations: 5HT: Serotonin; Ach: Acetylcholine; ANG II: Angiotensin II; ANOVA: Analysis of Variance; BAL: Bronchoalveolar Lavage; (D)-MWCNTs: MWCNT suspended in DPPC and RSA based medium; DPPC1: 2-dipalmitoyl-sn-glycero-3-phosphocholine; DPPC/ RSA DPPC: RSA and Phosphate Buffered Saline-based Medium; GD: Gestational Day; $\mathrm{EC}_{50}$ : Half-maximal Effective Concentration; Enos: Endothelial Nitric Oxide Synthase; IL1 $\beta$ : Interleukin 1 Beta; IL6: Interleukin 6; IL10: Interleukin 10; IFN $\gamma$ : Interferon, gamma; IT: Intratracheal Instillation; IV: Intravenous administration; MCP1: Monocyte Chemotactic Protein-1; MWCNT Multi-walled Carbon Nanotube; NP: Non-pregnant; P: Pregnant; PAI1: Plasminogen Activator Inhibitor-1; PE: Phenylephrine; PSS: Physiological Saline Solution; RAEC: Rat Aortic Endothelial Cells; (S)-MWCNTs: Multiwalled Carbon Nanotubes dispersed in 10\% surfactant; TNFa: Tumor Necrosis Factor, alpha; VEGF: Vascular Endothelial Growth Factor

\section{Introduction}

An increasing number of single- and multi-walled carbon nanotubes (SWCNTs and MWCNTs) are being designed and produced for various industrial and biomedical applications such as tracers of malignant cells, immunomodulators, contrast agents and as scaffolds in tissue engineering [1,2]. Pulmonary exposure to MWCNTs are reported to be associated with adverse effects similar to asbestos exposure [3] involving impairment in pulmonary functions [4] and activation of inflammatory responses in mesothelial cells [5]. MWCNTs are known to be taken-up by bronchial epithelial cells, increase pro-inflammatory cytokine production and induce cytotoxicity in in vitro studies [6,7].
When considering their bio-distribution, MWCNTs translocate to the lymph nodes following intratracheal instillation $[8,9]$ and potentially to other extra-pulmonary organs including the liver, kidney and heart and contributing to various toxico-pathologies [10]. The extrapulmonary effects of MWCNT exposure is reported to be associated with impairment of endothelium dependent relaxation in coronary arterioles [11] and increased coronary vascular tone enhancing indices of ischemia reperfusion injury [12]. The adverse pulmonary effects following occupational exposure to carbon nanotubes have been studied extensively in non-pregnant animal models $[9,13]$. The consequences of MWCNT exposure on the peripheral vascular system are yet to be studied adequately, particularly in the unique physiological stage of pregnancy.

In general, exposure to MWCNTs occurs by inhalation during occupational exposures in industry or in research laboratories [13-15].

*Corresponding author: Christopher J Wingard, Department of Physiology, Brody School of Medicine at East Carolina University, 600 Moye Boulevard, Brody 6N98, Greenville, NC, 27834, USA, Tel: +1-252-744-2804; Fax: +1-252-744-3460; E-mail: wingardc@ecu.edu

Received March 25, 2014; Accepted April 15, 2014; Published April 20, 2014

Citation: Vidanapathirana AK, Thompson LC, Odom J, Holland NA, Sumner SJ, et al. (2014) Vascular Tissue Contractility Changes Following Late Gestational Exposure to Multi-Walled Carbon Nanotubes or their Dispersing Vehicle in Sprague Dawley Rats. J Nanomed Nanotechnol 5: 201. doi:10.4172/2157-7439.1000201

Copyright: (C) 2014 Vidanapathirana AK, et al. This is an open-access article distributed under the terms of the Creative Commons Attribution License, which permits unrestricted use, distribution, and reproduction in any medium, provided the original author and source are credited. 
Citation: Vidanapathirana AK, Thompson LC, Odom J, Holland NA, Sumner SJ, et al. (2014) Vascular Tissue Contractility Changes Following Late Gestational Exposure to Multi-Walled Carbon Nanotubes or their Dispersing Vehicle in Sprague Dawley Rats. J Nanomed Nanotechnol 5: 201. doi:10.4172/2157-7439.1000201

Page 2 of 15

Potential biomedical applications could also expose an individual to MWCNTs primarily by the intravenous route [16]. An animal model study on MWCNT exposure during pregnancy reported minimal effects on fetal development and maternal well-being following oral exposure to $8-1000 \mathrm{mg} / \mathrm{kg} /$ day of MWCNTs [17]. The expansive vascular remodeling that takes place during pregnancy $[18,19]$ may predispose the maternal and fetal vasculature to be sensitive to nanomaterial exposures by various routes (i.e. pulmonary and intravenous) where increased concentrations of MWCNTs may directly reach the circulation. The consequence of any changes in vascular reactivity can potentially negatively influence the placental blood supply, impacting fetal growth and development. Following acute intravenous exposure, pristine carbon nanotubes are redistributed to the reticulo-endothelial system $[16,20]$ with a significant proportion remaining in blood [21]. This is in contrast to functionalized forms, which are reported to be excreted unchanged via the kidney $[22,23]$. It can be assumed that these nanotubes come in direct contact with the vascular endothelium during their circulation and these interactions can potentially induce changes in vascular reactivity during pregnancy by various mechanisms.

Multiplevasoconstrictoragents including phenylephrine, endothelin 1 , angiotensin II and serotonin act through $\mathrm{G}_{\mathrm{q}}$ protein coupled receptors to regulate smooth muscle contraction in the vasculature. Downstream of this receptor, the RhoA/Rho kinase pathway plays a critical role in mediating contractile response in vascular smooth muscle cells. The active form of RhoA promotes activation of the Rho kinase (ROCK) that inhibits MLC phosphatase (MLCP) activity, the dephosphorylation of myosin and subsequent relaxation [24]. Alterations in the RhoA/Rho kinase pathway is reported to be involved in endothelial dysfunction, inflammation [25,26] and with exposure to particulate matter [27].

We hypothesized that MWCNT exposure during pregnancy would increase the contractile responses in uterine and placenta derived blood vessels by increasing the RhoA/Rho kinase activity. We also hypothesized that there will be differential effects on the contractile responses dependent on the route of exposure and the vascular bed location. Intratracheal instillation and intravenous administration were used as the two routes of exposure to identify these differential effects within thoracic aorta, mesenteric and uterine arterial segments.

\section{Methods and Materials \\ MWCNT suspensions for exposure}

Multi-walled carbon nanotubes (MWCNTs) were a generous gift from NanoTechLabs Inc. (Yadkinville, NC, USA) and the dry powder form was previously characterized [4]. The commercial grade, nonfunctionalized, hydrophobic carbon based nanotubes were suspended in non-polar solvents/dispersion media prior to in vivo exposure. MWCNTs for intratracheal instillation was suspended in $10 \%$ clinical grade surfactant (Infasurf, ONY, Inc., Amherst, NY, USA), to mimic protein-lipid coating from lung surfactant, in sterile $0.9 \%$ saline $(0.9 \%$ $\mathrm{NaCl}, \mathrm{B}$. Braun Medical Inc., CA, USA) as previously described [4] to a concentration of $150 \mu \mathrm{g} / \mathrm{ml}$ and the mixture was cup-horn sonicated for 2 minutes at $65 \%$ amplitude for a total energy of 10,817 Joules, using a Misonix ultrasonic liquid processor -1510R-MTH (Branson Ultrasonics Corp. Danbury, CT, USA). This suspension will be referred to as "(S)MWCNTs" and had been previously characterized by Wang et al. [4]. Additionally, the MWCNTs were suspended in the dispersion media modified from Bihari et al. [28] for intravenous administration to coat with a vascular compartment protein. Briefly, this dispersion media contained $0.6 \mathrm{mg} / \mathrm{ml}$ rat serum albumin (Sigma, A6272), $0.01 \mathrm{mg} / \mathrm{ml}$ 1, 2-dipalmitoyl-sn-glycero-3-phosphocholine (DPPC, Sigma F-0763) in phosphate buffered saline (Sigma D5652 1X) and sonicated using the probe sonicator at $40 \%$ amplitude for 15 seconds. This dispersion medium will be referred to as "DPPC/RSA". A MWCNT suspension of $150 \mu \mathrm{g} / \mathrm{ml}$ was made with DPPC/RSA and the mixture was cup-horn sonicated using a Misonix ultrasonic liquid processor -1510R-MTH (Branson Ultrasonics Corp. Danbury, CT, USA) at 65\% amplitude for 2 minutes. This intravenous suspension will be referred to as "(D)MWCNTs" and was previously described by Wang et al. [29].

\section{Sprague Dawley rats}

Pregnant and non-pregnant female, 10-12 week old Sprague Dawley rats were purchased from Charles River Laboratories (USA). All rats were acclimated for one week in East Carolina University (ECU) Department of Comparative Medicine's animal facility, housed under 12 hour light/dark cycles with standard rat chow and water provided ad libitum. The pregnant rat arrived in the facility between 9-12 days of gestation and the body weight was monitored once in every three days to assess the progression of pregnancy. All animal handling and exposure procedures were approved by the ECU Institutional Animal Care and Use Committee.

\section{MWCNT exposure and dosing}

Each pregnant and non-pregnant female rat was randomly assigned to either the MWCNT exposure or dispersion medium control group for each route of exposure to include a minimum of six animals in a group. Matched gestational day pregnancies were used to compare vehicle vs. MWCNT effects. The pregnant rats were exposed between 17-19 days of gestation, compatible with the third trimester of human pregnancy (i.e. late gestational stage). Rats were anesthetized using 2-3\% isoflurane (Webster Veterinary, USA) dispersed in oxygen for exposure procedures. The $150 \mu \mathrm{g} / \mathrm{ml}$ MWCNT suspension was administered as a mass based dose of $100 \mu \mathrm{g} / \mathrm{kg}$ by weighing each rat just before the exposure. (S)-MWCNTs suspension or $10 \%$ surfactant was instilled intratracheally (IT) as previously described [4,12] for pulmonary exposure. A group of non-pregnant female rats was exposed to IT (S)MWCNTs or $10 \%$ surfactant to evaluate any effect of life stage (pregnant vs. non-pregnant) on vascular tissue contractility. Intravenous (IV) administration of $100 \mu \mathrm{g} / \mathrm{kg}$ (D)-MWCNTs or DPPC/RSA was done in the pregnant rats through the tail vein using a $25 \mathrm{G}$ needle. Ten to twelve weeks old, pregnant (GD 17-19) and non-pregnant female rats were used as naïve controls.

\section{Tissue and sample collection}

All rats were anesthetized in a transparent sealed receptacle containing gauze soaked with $70 \%$ isoflurane (Webster Veterinary, USA) in propylene glycol (Amersco, OH, USA), separated from the animal by a desiccator plate/grid prior to euthanasia. Twenty-four hours following administration of the MWCNTs or vehicle, the rats were subjected to a midline incision and euthanized by pneumothorax. Whole blood $(\sim 1 \mathrm{ml})$ was withdrawn directly from the maternal right ventricle. A pooled fetal blood sample was collected from three fetuses in each pregnant dam (blood from these three fetuses were considered as one sample). Maternal and fetal whole blood samples were centrifuged $\left(20,400 \mathrm{x} g\right.$ for 20 minutes), and serum supernatant was stored at $-80^{\circ} \mathrm{C}$ for cytokine analysis.

\section{Isolation of vessel segments}

Three arterial beds and the umbilical vein were selected for pharmacological myographic studies. The uterine and mesenteric vascular beds were selected as they manifest both structural and 
Citation: Vidanapathirana AK, Thompson LC, Odom J, Holland NA, Sumner SJ, et al. (2014) Vascular Tissue Contractility Changes Following Late Gestational Exposure to Multi-Walled Carbon Nanotubes or their Dispersing Vehicle in Sprague Dawley Rats. J Nanomed Nanotechnol 5: 201. doi:10.4172/2157-7439.1000201

Page 3 of 15

functional changes during pregnancy [30,31] with the uterine vasculature undergoing significant remodeling [32]. The thoracic aorta was included as proximal conduit vessel not anticipated to undergo significant remodeling, but still may express changes in pharmacological responses. Both uterine horns with the vascular arcades, small intestinal loop with superior mesenteric arcade and thoracic aorta were carefully excised and placed in ice cold physiological saline solution (PSS; $\mathrm{mM}$ ) $140 \mathrm{NaCl}, 5.0 \mathrm{KCl}, 1.6 \mathrm{CaCl}_{2}, 1.2 \mathrm{MgSO}, 1.2 \mathrm{MOPS}$ (3-[N-morpholino]propane sulfonic acid), 6 D-glucose, 0.02 EDTA, and a $\mathrm{pH}$ of 7.4). Arterial segments with a length of $0.5-2.0 \mathrm{~mm}$ were isolated from the mid region of the main uterine artery (diameter 150-300 $\mu \mathrm{m}$ ), first order mesenteric artery (diameter 150-250 $\mu \mathrm{m}$ ), and thoracic aorta (diameter 2-3 mm). Two umbilical vein segments (diameter 400-550 $\mu \mathrm{m})$ from umbilical cords of different fetuses implanted in the miduterine region were isolated from each dam.

\section{Maternal and fetal serum cytokine analysis}

The targets for maternal and fetal serum cytokine analysis were selected based on the reported cytokine targets in previous MWCNT exposure studies $[4,33,34]$. The selected serum cytokines and chemokines (IL6, IL10, TNFa, MCP1, VEGF, INF $\gamma$, and IL1 $\beta$ ) were assessed using Milliplex MAP Cytokine/Chemokine Panel and Immunoassay (EMD Millipore MA, USA) according to the manufacturer's directions. Assays were run using Luminex 100/200 (Luminex, Austin, TX) and results reported using Luminex xPONENT ${ }^{\circ}$ software versions $2.3 / 3.1$.

\section{Bronchoalveolar lavage cytology}

Twenty-four hours following exposure to MWCNTs or dispersion media, a bronchoalveolar lavage (BAL) was performed on adult female rats as described previously [4]. Briefly, the right lung was lavaged in situ three times with repeated flushes of $26.25 \mathrm{~mL} / \mathrm{kg}$ body weight of ice-cold Hanks balanced salt solution. The BAL fluids were centrifuged and the total number of cells was calculated using an automated cell counter (Cellometer, Nexcelom Bioscience, and Lawrence, MA, USA). A sample of 20,000 cells was centrifuged using a Cytospin IV (Shandon Scientific Ltd., Cheshire, UK) and stained with a three-step hematology stain (Richard Allan Scientific, Kalamazoo, MI, USA). The differential cell count was determined by morphology, evaluating 300 cells per slide using light microscopy and each cell count is reported as a percentage of 20,000 cells.

\section{Wire myographic studies}

The dissected vessel segments were mounted into a DMT 610M multi-channel wire myograph system (Danish Myo Technology, Aarhus N, Denmark) using $40 \mu \mathrm{m}$ wires or pins. All vessel segments were bathed in PSS at $37^{\circ} \mathrm{C}$, bubbled with medical grade air during the entire myographic studies. The optimal resting tension for each arterial segment was established at $90 \%$ of internal circumference (IC) produced at tensions equivalent to $100 \mathrm{mmHg}(13.3 \mathrm{kPa})$. A depolarization response with $\mathrm{K}^{+} \mathrm{PSS}\left(109 \mathrm{mM} \mathrm{K}{ }^{+}\right.$equal molar substitution of $\left.\mathrm{Na}^{+}\right)$was used to assess the vessel viability and segments that developed a stress response of greater than $1 \mathrm{mN} / \mathrm{mm}^{2}$ were considered viable. Endothelial viability was assessed by adding $3.0 \mu \mathrm{M}$ acetylcholine during a $1 \mu \mathrm{M}$ phenylephrine pre-contraction. Each segment along the arterial tree adapts to different hemodynamic conditions including blood pressure and autonomic innervations. Such adaptations will express different receptor classes and relative amounts of their subtypes, thus it is necessary to investigate different agonist responses in different vascular segments. All three arterial (uterine, mesenteric and aortic) vessel segments were subjected to cumulative concentrations of phenylephrine
(0.001-30 $\mu \mathrm{M})$, endothelin-1 (0.0001-1 $\mu \mathrm{M})$ and acetylcholine $(0.0001-$ $30 \mu \mathrm{M})$. Angiotensin II $(0.0001-0.1 \mu \mathrm{M})$ and serotonin $(0.001-1 \mu \mathrm{M})$ was used to study the uterine and mesenteric arteries respectively. The force generated by each vessel segment at each concentration was recorded using Lab Chart (ADI Instruments, CO, USA). The force was then normalized to the surface area of the vessel to determine the active stress generated in response to different agonists.

The umbilical vein segments were stretched and set to an IC equal to $90 \%$ of the IC when the wall tension is equivalent to $20 \mathrm{mmHg}(5.1 \mathrm{kPa})$ [35]. The viability was assessed using $\mathrm{K}^{+} \mathrm{PSS}$. The segments were precontracted with thromboxane-mimetic U46619 $(1 \mu \mathrm{M})$ and subjected to cumulative concentrations of acetylcholine $(0.0001-30 \mu \mathrm{M})$, followed by $1 \mu \mathrm{M}$ sodium nitroprusside.

\section{Cell culture, mRNA and protein quantification}

Rat aortic endothelial cells (RAEC) in the in vitro studies were used to identify the contribution of the endothelial RhoA/Rho kinase signaling following direct exposure to MWCNTs suspended in different media. RAEC were purchased from Cascade Biologics (Eugene, OR, USA), grown with Dulbecco's Modified Eagle Medium (DMEM) and cultured at $>90 \%$ confluence were treated with (S)-MWCNTs or (D)MWCNTs over a 1-10 $\mu \mathrm{g} / \mathrm{cm}^{2}$ dose range for 2-12 hours. Untreated cells, 10\% surfactant treated cells and DPPC/RSA treated cells were used as controls. Real time-PCR was done as described previously [24] to identify any changes RhoA, ROCK1, ROCK2 and eNOS mRNA expression following 2 hours of exposure to MWCNTs. Following 12hour in vitro exposure to MWCNTs or dispersion medium, In-Cell Western Assay (Li-Cor Biosciences, Lincoln, NE, USA) was performed to assess the changes in target protein expression [25] for RhoA, ROCK1, ROCK 2 and eNOS. The cell media was removed and the cells were immediately fixed with $3 \%$ formaldehyde followed by permeabilization with $0.1 \%$ Triton-X, blocked with Odyssey blocking buffer (LI-COR Biosciences, Lincoln, NE, USA). The primary antibodies for RhoA (1:1000), ROCK1 (1:500), ROCK2 (1:500) and eNOS (1:1000) (Santa Cruz Biotechnology Inc., USA and Cell Signaling Danvers, MA, USA) were added and plate incubated overnight. IRDye 800CW Secondary Antibodies (LI-COR Biosciences, Lincoln, NE, USA) were used in 1:10000 dilutions to identify target proteins. The DNA was stained with DRAQ5 and Sapphire 700 (Cell Signaling, Danvers, MA, USA) for cell number normalization. The Fluorescence was detected, quantified and analyzed using Li-Cor Odyssey Infrared Imaging System and software (LI-COR Biosciences, Lincoln, NE, USA).

\section{Measurement of the fetal and placental weight}

Body weights of pregnant dams were recorded just before sacrifice and the litter size was recorded before uterine vessel isolation. Three fetuses were isolated from each dam from the mid-uterine region and individual weights were measured using Ohaus Explorer Analytical Balance (Ohaus Corporation, NJ, USA). The blot weights of the placentae attached to the same fetuses were also recorded. The individual weights of the fetuses/placentae were then grouped according to the day of gestation at sacrifice and their mean weight was used for comparison between the treatment groups. Each day of gestation included the pups from at least 2 dams.

\section{Statistical analysis}

Statistical analysis was done utilizing GraphPad Prism 5 software (San Diego, CA) and data is presented as mean \pm SEM (standard error of mean). Repeated measures analysis of variance [36] and Bonferroni post hoc test were used to compare the concentration-responses of 
Citation: Vidanapathirana AK, Thompson LC, Odom J, Holland NA, Sumner SJ, et al. (2014) Vascular Tissue Contractility Changes Following Late Gestational Exposure to Multi-Walled Carbon Nanotubes or their Dispersing Vehicle in Sprague Dawley Rats. J Nanomed Nanotechnol 5: 201. doi:10.4172/2157-7439.1000201

Page 4 of 15

different agonists and the differences were considered statistically significant if $p<0.05$. In addition, each concentration-response curve was also compared across treatment groups using a regression analysis by examining the best-fit values [36]. $\mathrm{EC}_{50}$ values for concentrationresponses in myographic studies were determined using the Hill equation. A two tailed $\mathrm{t}$ test was used compare mean $\mathrm{EC}_{50}$, umbilical vein stress generation, and cytokine expression levels between different treatment and control groups. One way ANOVA and Turkey post-hoc test was used for the analysis of fetal and placental weight on each day of gestation.

\section{Results}

\section{Characterization of MWCNT suspensions}

The MWCNT suspension in $10 \%$ surfactant in saline [(S)MWCNTs] has been previously characterized by Wang et al. [4]. MWCNTs used in this study had a mean diameter of $22.5 \pm 1.3 \mathrm{~nm}$ with a bimodal distribution with peaks at 12.5 and $25 \mathrm{~nm}$ and a length range of $10-100 \mu \mathrm{m}$ and a surface area of $113.1 \mathrm{~m}^{2} / \mathrm{g}$ ). The zeta potential of the particles in (S)-MWCNTs suspension was $-57.3 \mathrm{mV}$ with a mean hydrodynamic size of $915 \mathrm{~nm}$. MWCNTs suspended in the DPPC, serum albumin and sterile phosphate buffered saline medium [(D)MWCNTs] was characterized previously by Wang et al. [29] with a zeta potential of $-20.8 \mathrm{mV}$ with a mean hydrodynamic size of $793 \mathrm{~nm}$.

\section{Maternal serum cytokine analysis}

The mean values serum cytokine levels of pregnant and nonpregnant rats 24 hours following exposure to MWCNTs or dispersion media for each route of exposure are reported in Table 1. The baseline cytokine levels in the naive rats were relatively higher in the nonpregnant group compared to the pregnant group for all cytokines assessed except VEGF. In general, the cytokine profiles for the rats exposed to vehicle or MWCNT were lower in the non-pregnant group while a few changes were noted in the pregnant group. IL1 $\beta$ level was increased by five fold in the pregnant group (when compared to the naive) following IV DPPC/RSA. TNFa levels were increased more than six fold in the serum following exposure to both dispersion media $(10 \%$ surfactant and DPPC/RSA) and increased with IV (D)-MWCNTs.

\section{Maternal Bronchoalveolar Lavage (BAL) cell counts}

The percentages of differential cell counts in the bronchoalveolar lavage fluid are graphed in Supplementary Figure 1 and MWCNT induced changes in these cell counts were observed only in the pregnant group. The mean percentage of macrophages was $4.2 \%$ lower in the naïve pregnant group compared to the naïve non-pregnant group, and increased during pregnancy following exposure to both vehicles (by $4.8 \%$ with $10 \%$ surfactant and by $5.0 \%$ with DPPC/RSA) and intravenous (D)-MWCNT exposure (by 4.3\%) compared to the naive. In contrast, the mean epithelial cell percentage was $4 \%$ higher in the naïve pregnant group compared to the naïve non-pregnant group and was reduced by $\sim 5 \%$ during pregnancy by following exposure to both vehicles and MWCNTs by both routes of exposure when compared to the naive. The percentage of neutrophils were highest following exposure to (S)-MWCNTs via intratracheal instillation but was less than $1 \%$ of the total BAL cell counts. The percentages of eosinophils were not significantly different following exposure to MWCNTs during pregnancy.

\section{Responses of arterial segments 24 hours post-exposure to intratracheal (IT) instillation of (S)-MWCNTs or $10 \%$ surfactant in pregnant and non-pregnant female rats}

The contractile responses of the vessel segments from the pregnant and non-pregnant rats were different following IT exposure to (S) MWCNTs. In general, the pregnant group manifested increased contractile responses in multiple vascular beds that were in part contributed to by the dispersal media as opposed to minimal changes in observed in the non-pregnant group.

\section{Main uterine artery}

The main uterine artery segments from pregnant and nonpregnant rats responded differently to the same dose of IT instilled (S)-MWCNTs. The maximum stress generation was increased in the pregnant group in response to phenylephrine by $2.6 \mathrm{mN} / \mathrm{mm}^{2}(+37 \%)$ following IT exposure to (S)-MWCNTs when compared to the naïve, but was not significantly increased when compared to the responses from $10 \%$ surfactant group (Figure 1A). The response to angiotensin II following IT exposure to (S)-MWCNT during pregnancy was increased by $4.9 \mathrm{mN} / \mathrm{mm}^{2}(+118 \%)$, as compared to the naïve and by $2.6 \mathrm{mN} / \mathrm{mm}^{2}(+40.7 \%)$ as compared to the $10 \%$ surfactant exposed group (Figure 1B). In contrast, the stress generation in response to all 3 agonists was diminished in uterine artery segments from non-pregnant animals following (S)-MWCNTs exposure (Figure 1B, D and F). The relaxation responses to acetylcholine during $30 \mu \mathrm{M}$ phenylephrine pre-contraction were not different in naive, $10 \%$ surfactant and (S)MWCNTs exposed pregnant groups (Figure 1G), but was diminished $\sim 10 \%$ following $(\mathrm{S})$-MWCNTs exposure in the non-pregnant group

\begin{tabular}{|c|c|c|c|c|c|c|c|c|}
\hline Cytokine & NP-naive & $\begin{array}{c}\text { NP-IT } \\
10 \% \text { surfactant }\end{array}$ & $\begin{array}{c}\text { NP- IT } \\
\text { (S)-MWCNTs }\end{array}$ & P-naive & $\begin{array}{c}\text { P-IT } \\
10 \% \text { surfactant }\end{array}$ & $\begin{array}{c}\text { P-IT } \\
\text { (S)-MWCNTs }\end{array}$ & $\begin{array}{c}\text { P-IV } \\
\text { DPPC/RSA }\end{array}$ & $\begin{array}{c}\text { P-IV } \\
\text { (D)-MWCNTs }\end{array}$ \\
\hline IL1 $\beta$ (pg/ml) & $56.0 \pm 38.5$ & $10.1 \pm 3.8$ & $7.3 \pm 5.4$ & $14.6 \pm 7.1^{\dagger}$ & $42.1 \pm 7.1$ & $15.8 \pm 5.7^{*}$ & $70.2 \pm 17.3^{\#}$ & $45.0 \pm 12.5$ \\
\hline IL6 (pg/ml) & $1245.0 \pm 826.0$ & $640.0 \pm 208.2$ & $485.0 \pm 209.0$ & $77.9 \pm 72.8$ & $215.3 \pm 62.6$ & $183.0 \pm 128.8$ & $126.8 \pm 92.1$ & $229.4 \pm 115.5$ \\
\hline IL10 (pg/ml) & $21.7 \pm 9.0$ & $13.4 \pm 4.8$ & $10.2 \pm 6.4$ & $5.8 \pm 3.7$ & $9.6 \pm 4.4$ & $7.3 \pm 3.6$ & $16.4 \pm 6.0$ & $9.8 \pm 4.2$ \\
\hline INFY (pg/ml) & $338.4 \pm 135.3$ & $189.6 \pm 33.6$ & $174.1 \pm 57.3$ & $198.5 \pm 50.5$ & $106.4 \pm 10.8$ & $131.0 \pm 36.8$ & $273.1 \pm 102.2$ & $242.0 \pm 50.1$ \\
\hline MCP1 (pg/ml) & $823.2 \pm 223.9$ & $467.0 \pm 106.6$ & $540.2 \pm 248.9$ & $288.1 \pm 96.0^{+}$ & $492.9 \pm 27.0$ & $336.2 \pm 96.5$ & $510.6 \pm 54.8$ & $478.2 \pm 36.2$ \\
\hline VEGF $(\mathrm{pg} / \mathrm{ml})$ & $53.7 \pm 15.4$ & $30.1 \pm 4.3$ & $29.4 \pm 7.5$ & $510.2 \pm 111.9^{+}$ & $377.4 \pm 81.1^{\dagger}$ & $476.6 \pm 42.2^{+}$ & $421.8 \pm 63.0$ & $432.8 \pm 56.6$ \\
\hline TNFa (pg/ml) & $40.9 \pm 12.83$ & $30.3 \pm 4.6$ & $27.0 \pm 8.9$ & $6.8 \pm 3.9^{+}$ & $45.3 \pm 10.2^{\#}$ & $23.9 \pm 9.9$ & $43.7 \pm 13.3^{\#}$ & $34.1 \pm 10.4^{\#}$ \\
\hline
\end{tabular}

IT: intratracheal instillation and IV: intravenous administration, P: pregnant and NP: non-pregnant, N/A: not available

MWCNT: Multi-wall carbon nanotube, $\mathbf{1 0} \%$ surfactant: $10 \%$ surfactant in saline, (S)-MWCNTs: MWCNT suspended in $10 \%$ surfactant, DPPC/RSA: vehicle used for IV MWCNT delivery and (D)-MWCNTs: MWCNT suspended in DPPC/RSA.

*indicates $p<0.05$ when compared to the dispersion medium of each route, \#indicates $p<0.05$ when compared to naïve and

tindicates $p<0.05$ when compared to same treatment in non - pregnant.

Table 1: Cytokine levels in maternal serum 24 hours post-exposure to MWCNTs.

The maternal serum cytokines were evaluated using Milliplex MAP Cytokine/Chemokine Panel and Immunoassay (EMD Millipore MA, USA). The assays were run using Luminex 100/200 (Luminex, Austin, TX) and results reported using Luminex xPONENT ${ }^{\circledR}$ software versions 2.3/3.1. The mean and the SEM are reported for serum cytokines of pregnant and non-pregnant female Sprague Dawley rats $(n=5-8)$. 
Citation: Vidanapathirana AK, Thompson LC, Odom J, Holland NA, Sumner SJ, et al. (2014) Vascular Tissue Contractility Changes Following Late Gestational Exposure to Multi-Walled Carbon Nanotubes or their Dispersing Vehicle in Sprague Dawley Rats. J Nanomed Nanotechnol 5 : 201. doi:10.4172/2157-7439.1000201

\section{Main uterine artery}

\section{Pregnant}

A

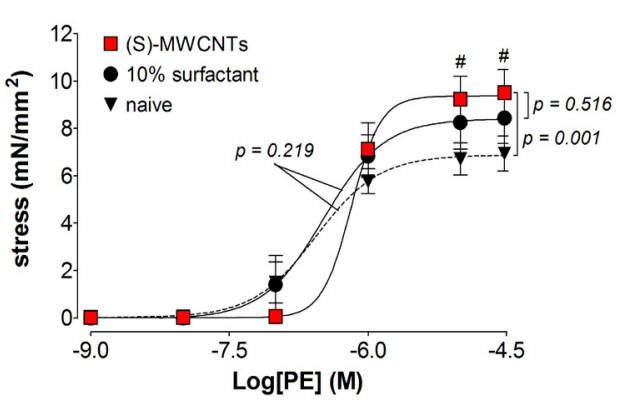

c

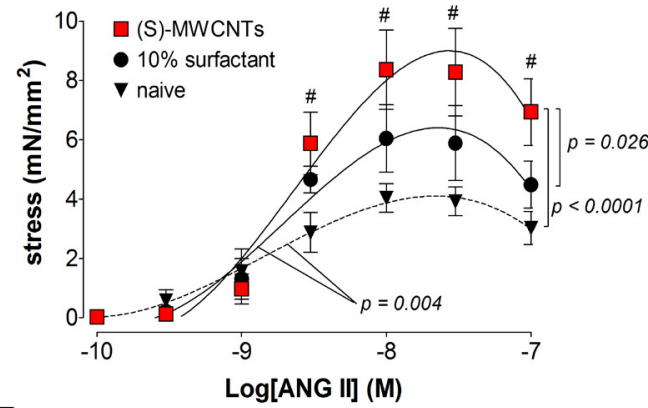

$\mathbf{E}$

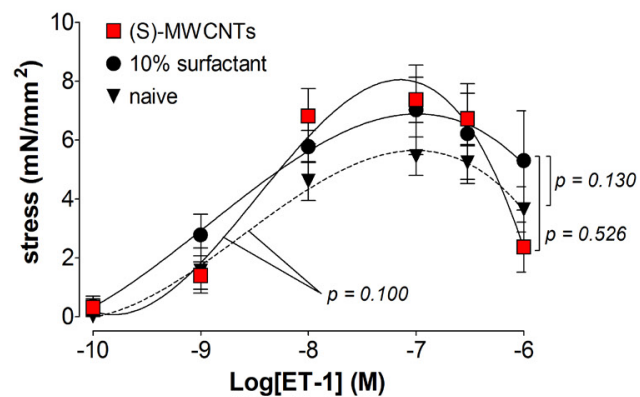

G

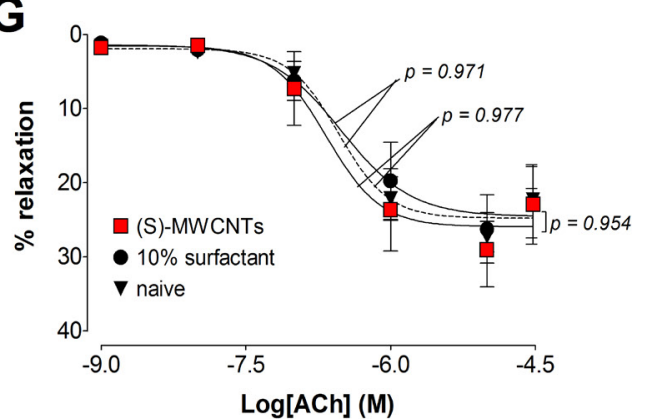

Non-pregnant

B

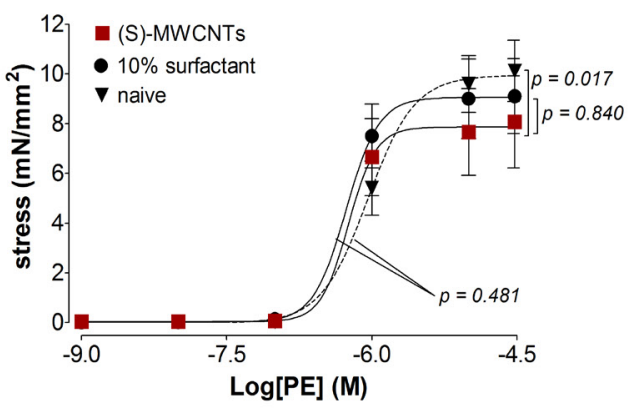

D

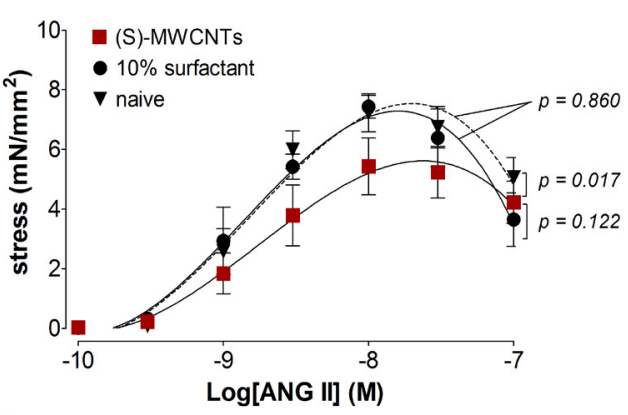

$\mathbf{F}$

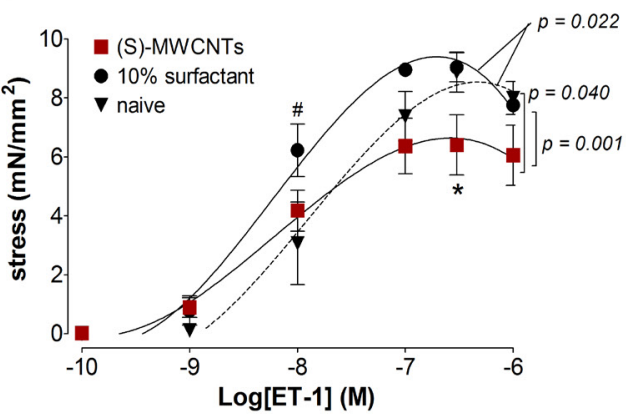

H

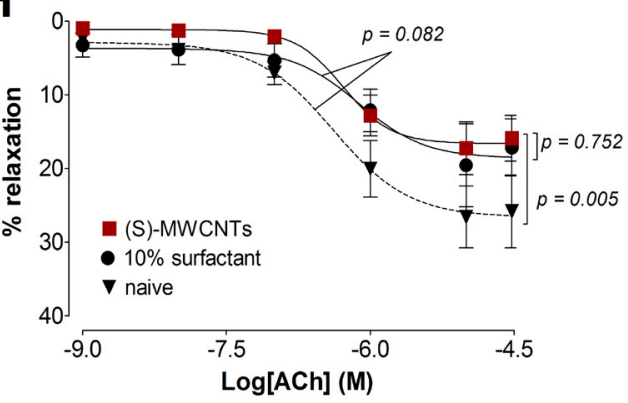

Figure 1: Changes in the contractile responses of the main uterine artery following intratracheal instillation (IT) of MWCNTs

The changes in the contractile responses as assessed by wire myography of the main uterine artery from $17-19$ days pregnant (A, C, E and $\mathbf{G})$ and non-pregnant female (B, D, F and H) Sprague Dawley rats, 24 hours following intratracheal instillation of $100 \mu \mathrm{g} / \mathrm{kg}$ of (S)-MWCNTs or $10 \%$ surfactant. The stress generation in response to cumulative concentrations of phenylephrine (PE; A and B), angiotensin II (ANG II; $\mathbf{C}$ and $\mathbf{D}$ ) and endothelin 1 (ET-1; $\mathbf{E}$ and $\mathbf{F}$ ) are plotted. The percentage relaxation from a $30 \mu \mathrm{M}$ phenylephrine pre-stimulation stress level in response to cumulative concentrations of acetylcholine (Ach; $\mathbf{G}$ and $\mathbf{H})$ is graphed. * indicates $p$ $<0.05$ compared to $10 \%$ surfactant while $\#$ indicates $p<0.05$ compared to naïve using repeated measures ANOVA ( $n=5-7)$. The $p$ values were derived following the comparison of each concentration response curve across treatment groups using a regression analysis by examining the best-fit values. 
Citation: Vidanapathirana AK, Thompson LC, Odom J, Holland NA, Sumner SJ, et al. (2014) Vascular Tissue Contractility Changes Following Late Gestational Exposure to Multi-Walled Carbon Nanotubes or their Dispersing Vehicle in Sprague Dawley Rats. J Nanomed Nanotechnol 5 : 201. doi:10.4172/2157-7439.1000201

(Figure $1 \mathrm{H}$ ). The calculated $\mathrm{EC}_{50}$ values for phenylephrine, angiotensin II, , acetylcholine and HA-1077 were not different between the naive, $10 \%$ surfactant and (S)-MWCNTs treatment groups. Following (S)-MWCNTs exposure in pregnant rats, calculated $\mathrm{EC}_{50}$ value for endothelin $1(1.1 \pm 0.3 \mathrm{nM})$ was significantly lower than the naive (3.4 $\pm 0.6 \mathrm{nM}$ ), but not different form the $10 \%$ surfactant exposed group $(2.2 \pm 1.0 \mathrm{nM}$, Supplementary Table 1).

\section{First order mesenteric artery}

The mesenteric artery segments from both pregnant and nonpregnant rats responded in a similar manner following IT (S)MWCNT exposure. The stress generations in response to serotonin in the first order mesenteric artery segments were increased by $\sim 4$ $\mathrm{mN} / \mathrm{mm}^{2}$ following IT (S)-MWCNTs exposure compared to $10 \%$ surfactant exposed group (Figure 2E and F). The contractile responses

\section{Mesenteric artery \\ Pregnant \\ Non-pregnant}

A

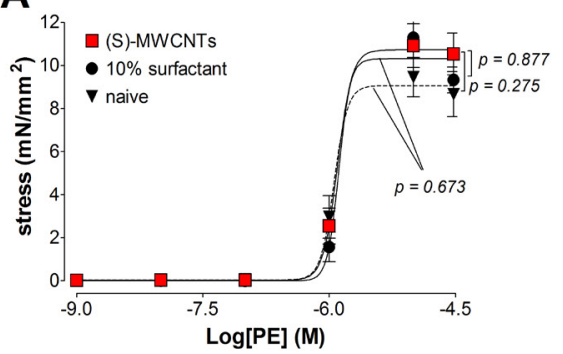

C

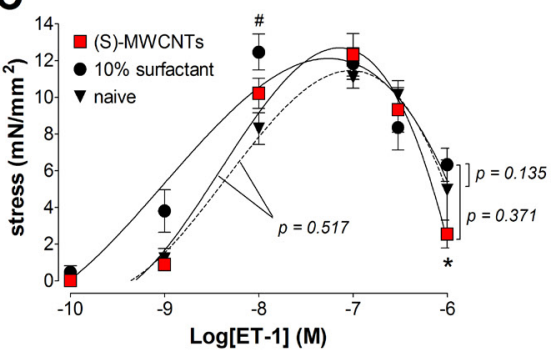

E
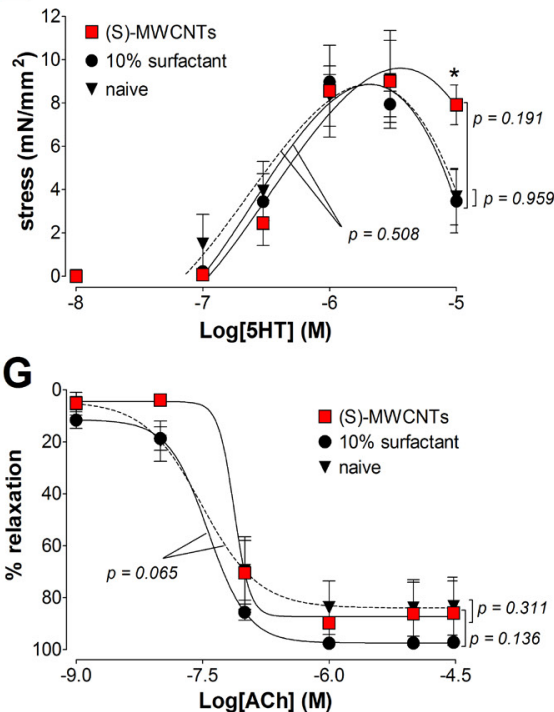

B

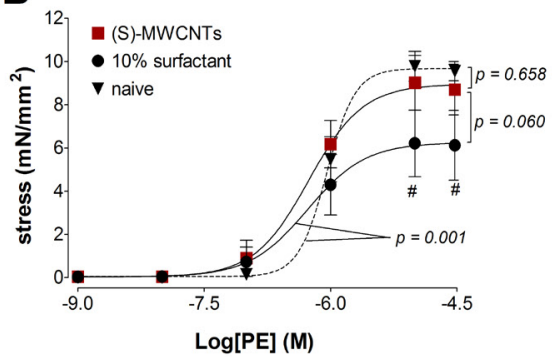

D

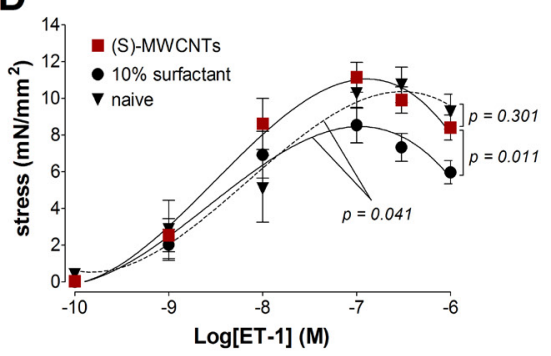

$\mathbf{F}$

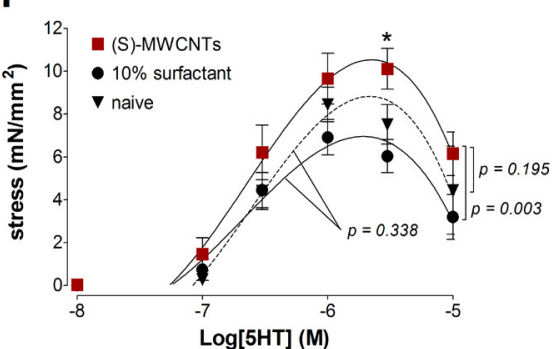

H

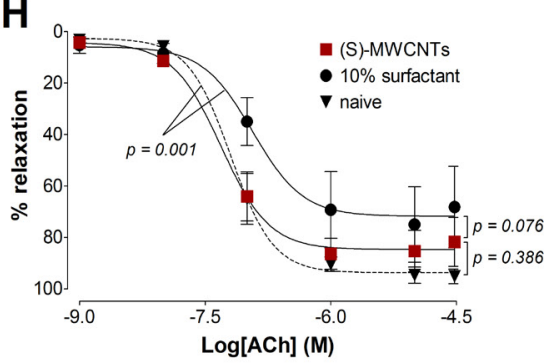

Figure 2: Changes in the contractile responses of the mesenteric artery following intratracheal instillation (IT) of MWCNTs

The changes in the contractile responses were assessed by wire myography of the first order mesenteric artery from 17 - 19 days pregnant (A, C, E and G) and nonpregnant female (B, D, F and H) Sprague Dawley rats, 24 hours following intratracheal instillation (IT) of $100 \mu \mathrm{g} / \mathrm{kg}$ of (S)-MWCNTs or $10 \%$ surfactant. The stress generation in response to cumulative concentrations of phenylephrine (PE; $\mathbf{A}$ and $\mathbf{B}$ ), endothelin 1 ( $E T-1 ; \mathbf{C}$ and $\mathbf{D})$ and serotonin (5HT; $\mathbf{E}$ and $\mathbf{F})$ are plotted. The percentage relaxation from a $30 \mu \mathrm{M}$ phenylephrine pre-stimulation stress level in response to cumulative concentrations of acetylcholine (Ach; $\mathbf{G}$ and $\mathbf{H})$ is graphed. * indicates $p<0.05$ compared to $10 \%$ surfactant while \# indicates $p<0.05$ compared to naïve using repeated measures ANOVA $(n=4-7)$. The $p$ values were derived following the comparison of each concentration response curve across treatment groups using a regression analysis by examining the best-fit values. 
Citation: Vidanapathirana AK, Thompson LC, Odom J, Holland NA, Sumner SJ, et al. (2014) Vascular Tissue Contractility Changes Following Late Gestational Exposure to Multi-Walled Carbon Nanotubes or their Dispersing Vehicle in Sprague Dawley Rats. J Nanomed Nanotechnol 5 : 201. doi:10.4172/2157-7439.1000201

to phenylephrine or endothelin 1 and the relaxation response to acetylcholine were not changed following IT (S)-MWCNT exposure in the pregnant group (Figure $2 \mathrm{~A}, \mathrm{C}$ and $\mathrm{G}$ ).

The mesenteric artery contractile responses to all 3 agonists were diminished in the non-pregnant rats exposed to $10 \%$ surfactant (Figure 2B, D and F), along with an impairment of acetylcholine dependent relaxation response (Figure $2 \mathrm{H}$ ). Similar to the reported uterine vessels responses, the $\mathrm{EC}_{50}$ values of the mesenteric arteries responses following (S)-MWCNT exposure were not different except for endothelin 1 (Supplementary Table 2). The $\mathrm{EC}_{50}$ for endothelin 1-mediated responses was decreased in the $10 \%$ surfactant $(1.4 \pm 0.4$ $\mathrm{nM})$ group when compared to both naïve $(5.4 \pm 1.3 \mathrm{nM})$ and (S)MWCNTs exposed group $(5.0 \pm 1.0 \mathrm{nM})$.

\section{Thoracic aorta}

The thoracic aortic segments from pregnant and non-pregnant rats responded differently to the IT exposure to (S)-MWCNTs. The contractile response to phenylephrine $(0.001-10 \mu \mathrm{M})$ was reduced by $0.68 \mathrm{mN} / \mathrm{mm}^{2}(25.4 \%)$ in the pregnant group following (S)-MWCNT exposure compared to the naïve, but was not different when compared to the $10 \%$ surfactant exposed group (Figure 3A). The contractile

Thoracic aorta

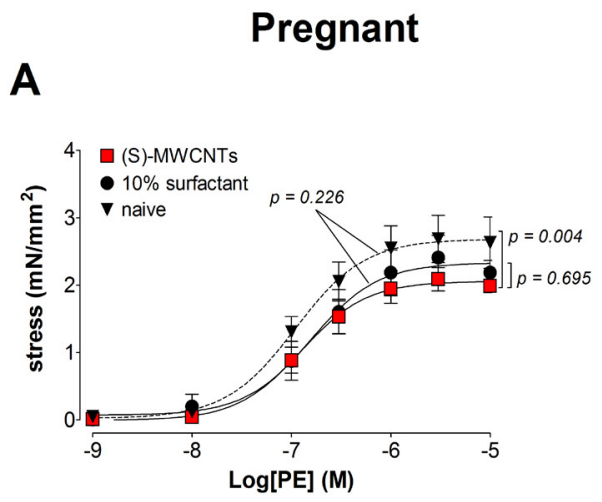

C

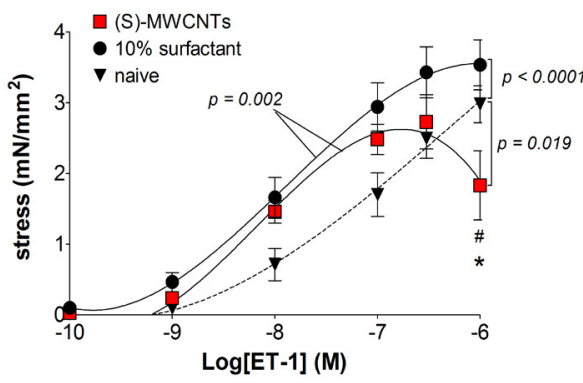

E

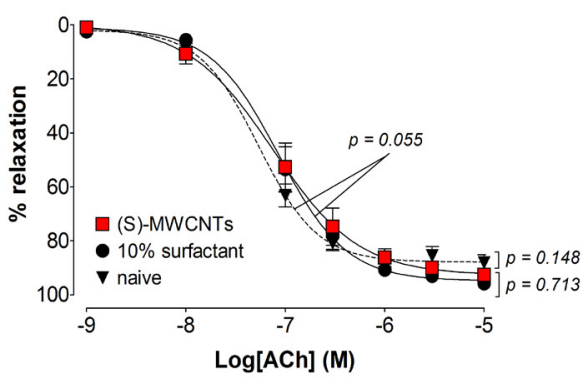

B

Non-pregnant

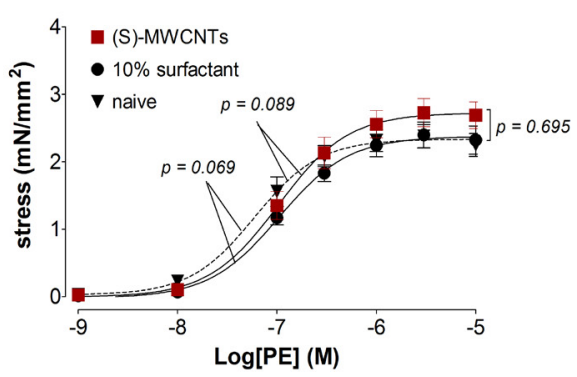

D

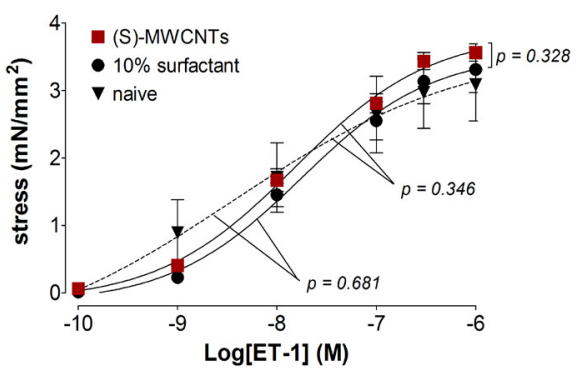

F

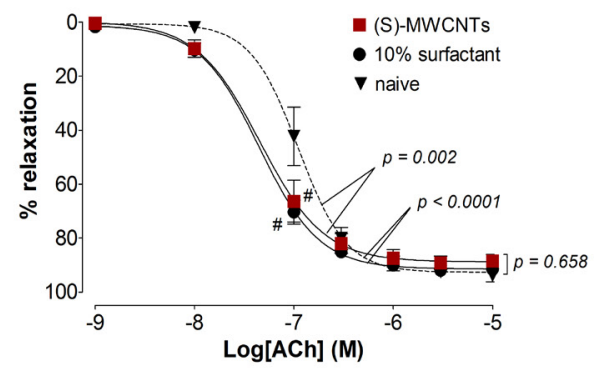

Figure 3: Changes in the contractile responses of the thoracic aorta following intratracheal instillation (IT) of exposure to MWCNTs.

The changes in the contractile responses were assessed by wire myography of the thoracic aorta from 17 - 19 days pregnant (A, C and $\mathbf{E})$ and non-pregnant female (B, D and F) Sprague Dawley rats, 24 hours following intratracheal instillation of $100 \mu \mathrm{g} / \mathrm{kg}$ of (S)-MWCNTs or $10 \%$ surfactant. The stress generation in response to cumulative concentrations of phenylephrine (PE; $\mathbf{A}$ and $\mathbf{B})$ and endothelin $1(\mathrm{ET}-1 ; \mathbf{C}$ and $\mathbf{D})$ are plotted. The percentage relaxation form a $10 \mu \mathrm{M}$ phenylephrine prestimulation stress level in response to cumulative concentrations of acetylcholine (Ach; $\mathbf{E}$ and $\mathbf{F}$ ) is graphed. * indicates $p<0.05$ compared to $10 \%$ surfactant while ${ }^{*}$ indicates $p<0.05$ compared to naïve using repeated measures ANOVA $(n=4-8)$. The $p$ values were derived following the comparison of each concentration response curve across treatment groups using a regression analysis by examining the best-fit values. 
Citation: Vidanapathirana AK, Thompson LC, Odom J, Holland NA, Sumner SJ, et al. (2014) Vascular Tissue Contractility Changes Following Late Gestational Exposure to Multi-Walled Carbon Nanotubes or their Dispersing Vehicle in Sprague Dawley Rats. J Nanomed Nanotechnol 5 : 201. doi:10.4172/2157-7439.1000201

Page 8 of 15

response to endothelin 1 from the pregnant thoracic aorta segments was increased in both (S)-MWCNTs and $10 \%$ surfactant exposed groups when compared to the naïve. There was a noticeable relaxation response to highest concentration of endothelin 1 in the (S)-MWCNT exposed pregnant group (Figure 3C). In contrast, the contractile responses to phenylephrine and endothelin 1 were not affected by (S)MWCNT or $10 \%$ surfactant exposure in the non-pregnant female rats (Figure $3 \mathrm{~B}$ and $\mathrm{D}$ ).

The acetylcholine $(0.001-10 \mu \mathrm{M})$ mediated relaxation response was not different in the pregnant group (Figure 3E), but was increased in both (S)-MWCNTs and 10\% surfactant exposed non-pregnant aortic segments when compared to the naïve (Figure $3 \mathrm{~F}$ ). The $\mathrm{EC}_{50}$ values were not different for the contractile and relaxation responses following (S)MWCNT exposure (Supplementary Table 3).

Responses of arterial segments 24 hours post-exposure to intravenous (IV) administration (D)-MWCNTs or DPPC/ RSA in pregnant rats

Twenty four hours following IV administration in pregnant rats, both (D)-MWCNTs and DPPC/RSA increased the maximal stress generation in the main uterine artery segments to a similar magnitude $\left(3-4 \mathrm{mN} / \mathrm{mm}^{2}\right)$ when compared to naive vessel segments with a similar concentration-response profile for the agonists: phenylephrine, endothelin 1 and angiotensin II (Figure 4A-C). The DPPC/RSA exposure elevated the baseline stress level of the uterine vessel segments while the (D)-MWCNTs exposure had no additional effect. The relaxation responses of the main uterine artery to acetylcholine were not changed by IV (D)-MWCNT or DPPC/RSA exposure (Figure 4D). We did not proceed to do non-pregnant comparisons in this exposure group as the differences in the contractile responses were attributed sole to DPPC/RSA suspension and not to MWCNT exposure.

An increase in contractile response in the mesenteric artery segments was seen at higher concentrations of phenylephrine following (D)-MWCNT exposure (supplementary Figure 2A). All other contractile/relaxation responses of the mesenteric artery and aortic segments were not significantly different between the (D)MWCNTs or DPPC/RSA exposure groups (supplementary Figures $2 \mathrm{~B}-\mathrm{D}$ and $3 \mathrm{~A}-\mathrm{C})$. Unlike in the uterine artery, DPPC/RSA did not have a significant effect on the baseline stress level of the mesenteric artery or thoracic aorta. The $\mathrm{EC}_{50}$ values for all responses are reported in supplementary Tables 1-3 and were not different with the exception for endothelin 1, where the $\mathrm{EC}_{50}$ was reduced in the in the thoracic aortic segments following (D)-MWCNTs $(13.3 \pm 5.1 \mathrm{nM})$ or DPPC/ RSA $(12.4 \pm 5.1 \mathrm{nM})$ exposure when compared to the naïve (71.9 \pm $17.8 \mathrm{nM}$, Supplementary Table 3 ).

\section{Contribution of Rho kinase activity on the vascular tissue} contractility following exposure to MWCNTs

Maintenance of stress in the presence of Rho kinase inhibitor: Minor differences were observed in the relaxation responses to cumulative concentrations of the Rho kinase (ROCK) inhibitor, HA1077, during the stable phenylephrine pre-contraction for segments from all three vascular beds, regardless of the pregnancy state or route of exposure to the MWCNT (Figure 5 and Supplementary Figure 4). The $\mathrm{EC}_{50}$ values for the concentration responses are reported in Supplementary Tables 1-3 and were not significantly different following MWCNT exposure except within the IV (D)-MWCNT exposure group during pregnancy $(2.6 \pm 0.2 \mu \mathrm{M}$ compared to $1.8 \pm 0.3 \mu \mathrm{M}$ in the DPPC/ RSA exposed group).

\section{Main uterine artery}

A

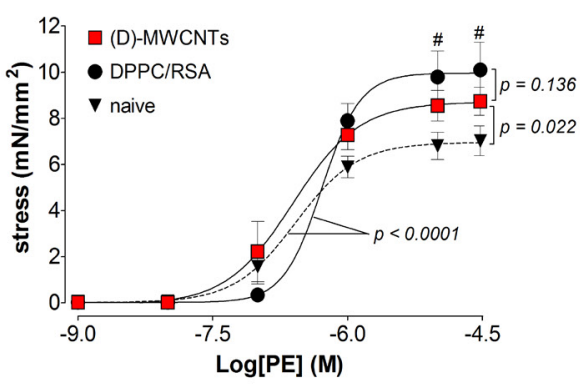

B

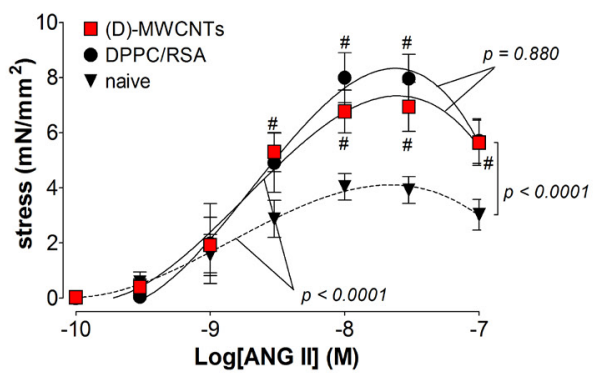

C

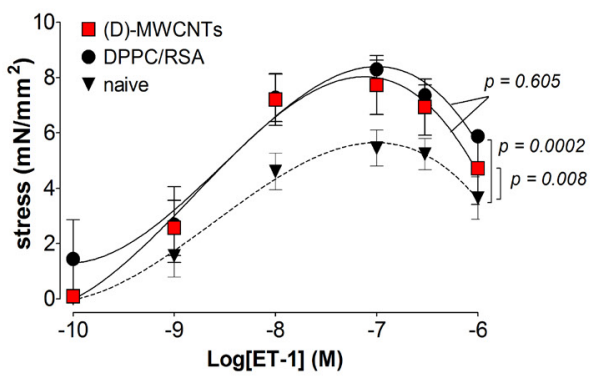

D

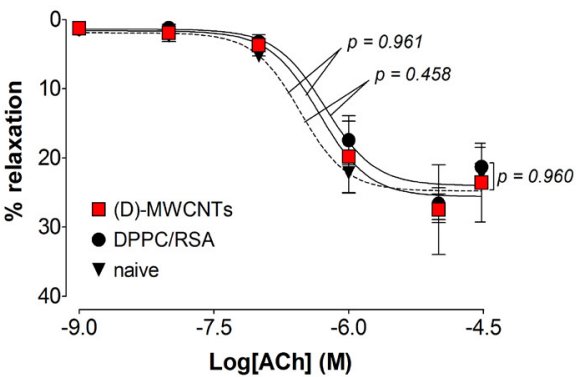

Figure 4: Changes in the contractile responses of the main uterine artery following intravenous administration (IV) of MWCNTs.

The changes in the contractile responses were assessed by wire myography of the main uterine artery segments from $17-19$ days pregnant $(\mathbf{A}, \mathbf{B}, \mathbf{C}$ and D) Sprague Dawley rats, 24 hours following intravenous administration of 100 $\mu \mathrm{g} / \mathrm{kg}$ of (D)-MWCNTs or DPPC/RSA. The stress generation in response to cumulative concentrations of phenylephrine (PE; A), angiotensin II (ANG II; B) and endothelin $1(\mathrm{ET}-1 ; \mathbf{C})$ are plotted. The percentage relaxation from a $30 \mu \mathrm{M}$ phenylephrine pre-stimulation stress level in response to cumulative concentrations of acetylcholine is graphed (Ach: D). \# indicates $p<0.05$ compared to naïve using repeated measures ANOVA $(n=5-8)$. The $p$ values were derived following the comparison of each concentration response curve across treatment groups using a regression analysis by examining the best-fit values. 


\section{Pregnant}

\section{Non-pregnant}

\section{Main uterine artery}

A

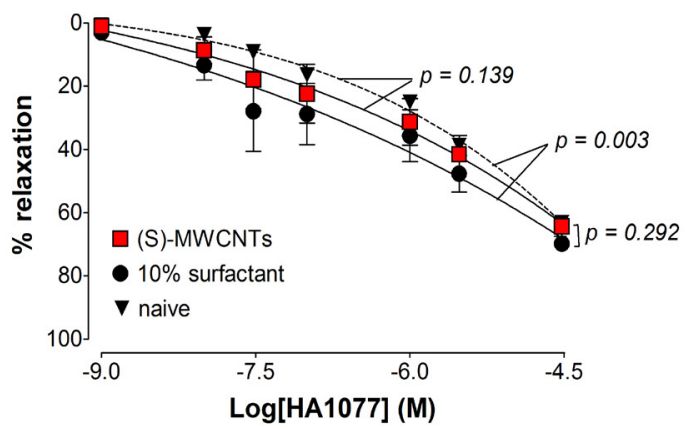

B

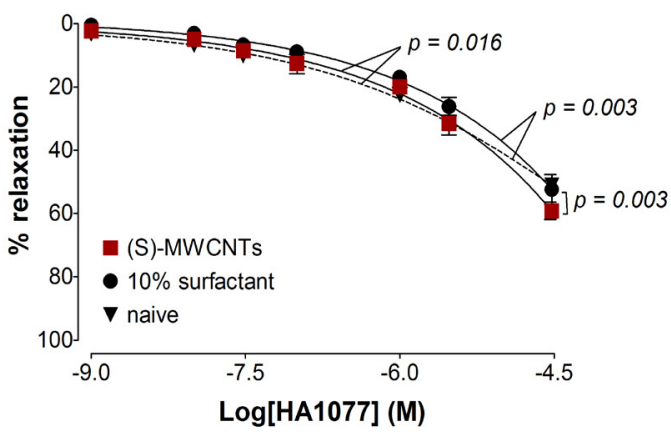

\section{Mesenteric artery}

C

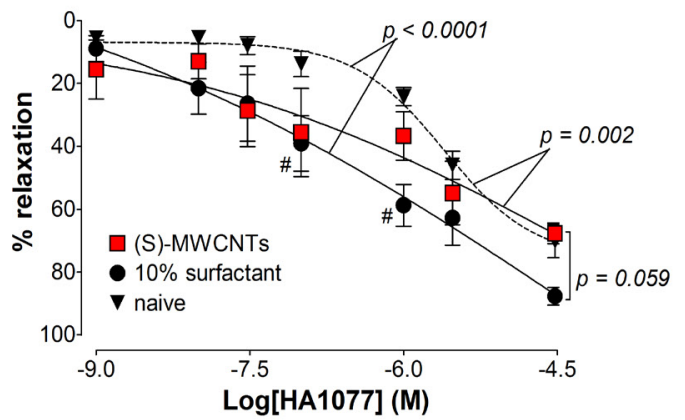

D

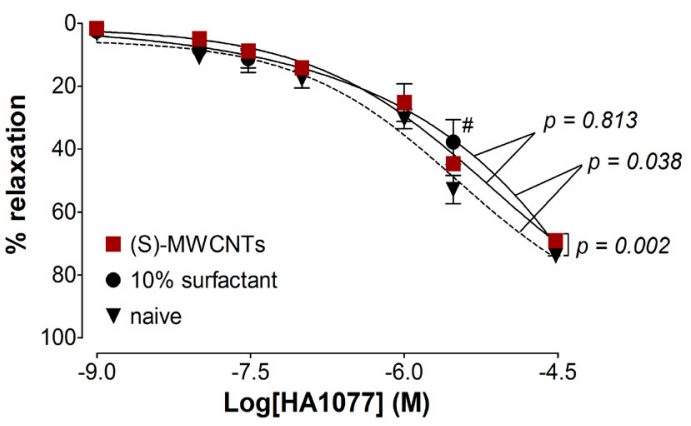

Thoracic aorta
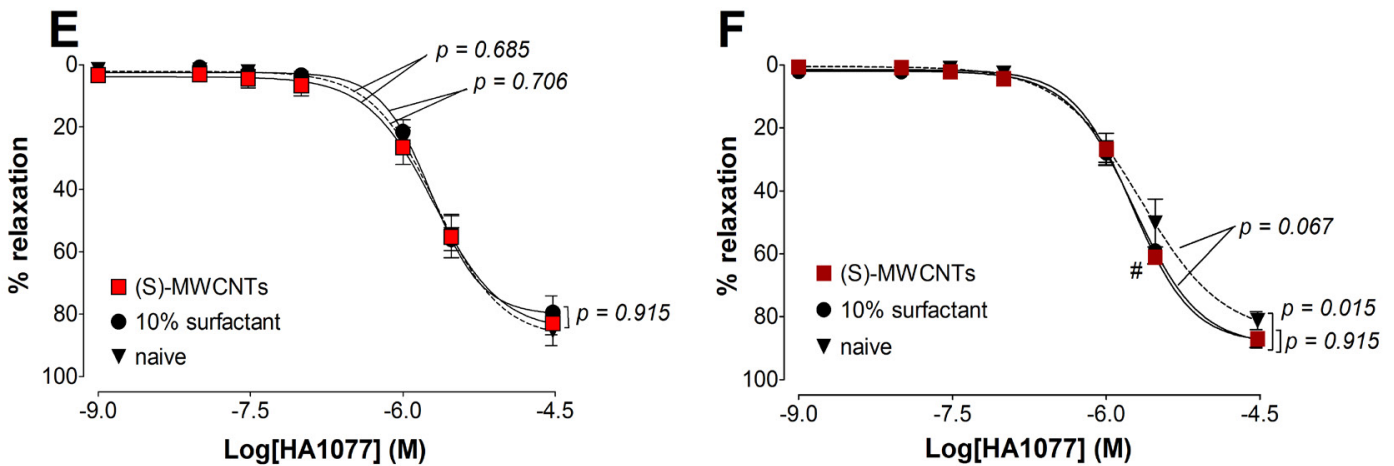

Figure 5: Changes in stress generation in the presence of a Rho kinase inhibitor following intratracheal instillation (IT) MWCNTs.

The reduction in stress generation is reported as the percentage relaxation from a phenylephrine (30 $\mu \mathrm{M}$ for uterine/mesenteric arteries and $10 \mu \mathrm{M}$ for aorta) prestimulation stress level in response to cumulative additions of a Rho kinase inhibitor (HA1077). All responses were assessed by wire myography, 24 hours following intratracheal instillation of $100 \mu \mathrm{g} / \mathrm{kg}$ of (S)-MWCNTs or $10 \%$ surfactant from 17 - 19 days pregnant (A, C and E) and non-pregnant female (B, D and F) Sprague Dawley rats. Panels $\mathbf{A}$ and $\mathbf{B}$ : main uterine artery; $\mathbf{C}$ and $\mathbf{D}$ : first order mesenteric artery; $\mathbf{E}$ and $\mathbf{F}$ : thoracic aorta. ${ }^{\#}$ indicates $p<0.05$ compared to naïve using repeated measures ANOVA ( $n=4-6$ ). The $p$ values were derived following the comparison of each concentration response curve across treatment groups using a regression analysis by examining the best-fit values. 
Citation: Vidanapathirana AK, Thompson LC, Odom J, Holland NA, Sumner SJ, et al. (2014) Vascular Tissue Contractility Changes Following Late Gestational Exposure to Multi-Walled Carbon Nanotubes or their Dispersing Vehicle in Sprague Dawley Rats. J Nanomed Nanotechnol 5: 201. doi:10.4172/2157-7439.1000201

Page 10 of 15

RhoA, ROCK and eNOS mRNA and protein expression in rat aortic endothelial cells: The mRNA expression of RhoA, ROCK1, ROCK2 and $e N O S$ was not significantly changed in RAEC with 2-12 hour treatment with (S)-MWCNTs or (D)-MWCNTs when compared to untreated cells and vehicle controls (data not shown). Similarly, the protein expression of RhoA, ROCK and eNOS were not changed with 12 hours in vitro exposure to $10 \mu \mathrm{g} / \mathrm{cm}^{2}$ of (S)-MWCNTs or (D)MWCNTs as assessed by the In-cell Western Assay (Supplementary Figures 5 and 6).

\section{IT (S)-MWCNTs}

\section{A}

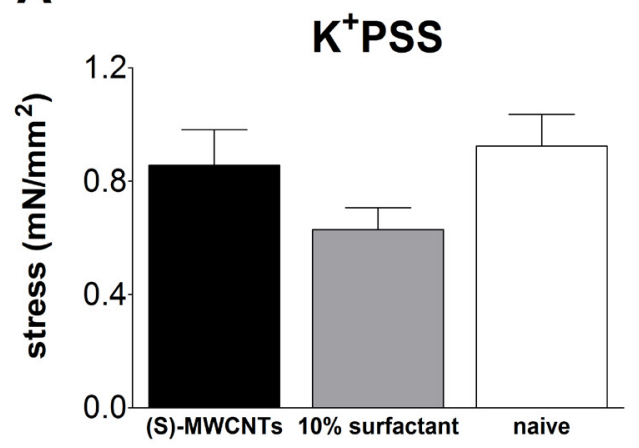

C

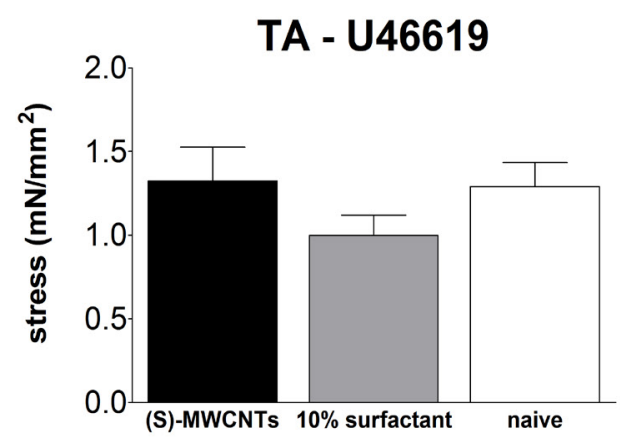

E

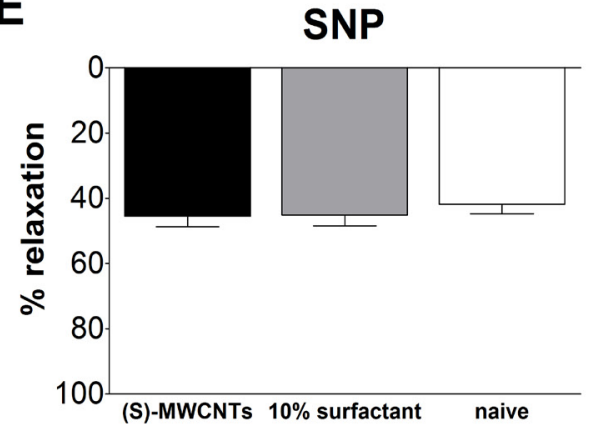

IV (D)-MWCNTs

B

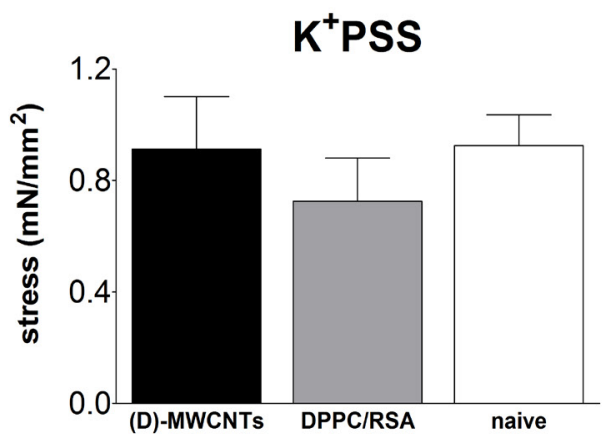

D

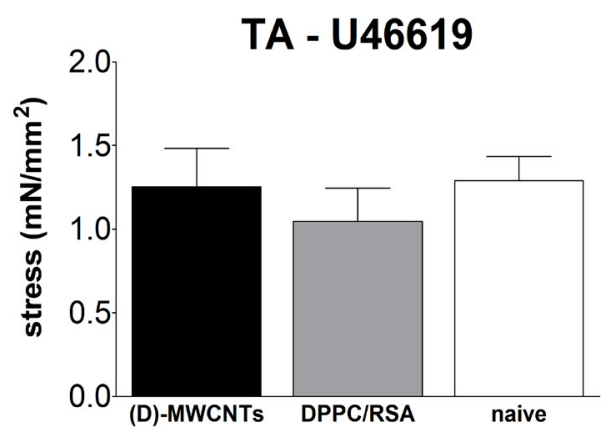

F

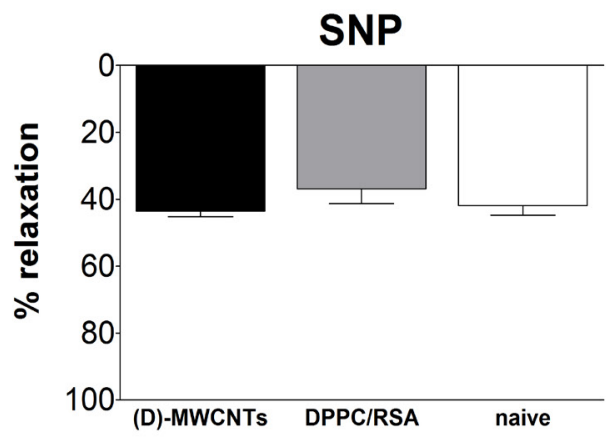

Figure 6: Changes in contractile responses of the umbilical vein following maternal exposure to MWCNTs.

The changes stress generation in the umbilical vein segments were assessed by wire myography in response to $109 \mathrm{mM} \mathrm{K}^{+}$depolarization $(\mathbf{A}$ and $\mathbf{B})$ and $1 \mu \mathrm{M}$ thromboxane agonist (U46619, B and D) 24 hours post- exposure to intratracheal instillation (IT) of $100 \mu \mathrm{g} / \mathrm{kg}$ of (S)-MWCNTs or $10 \%$ surfactant (A and C) or intravenous administration (IV) of (D)-MWCNTs or DPPC/RSA (B and D), from 17 - 19 days pregnant Sprague Dawley rats $(n=12)$. The percentage relaxation in response to sodium nitroprusside (SNP) following U46619 (1 $\mu \mathrm{M})$ pre-contraction in the umbilical vein 24 hours post- exposure to intratracheal instillation of $(\mathrm{S})$ MWCNTs or $10 \%$ surfactant (E) or intravenous administration of (D)-MWCNT or DPPC/RSA is graphed $(\mathbf{F})(n=12)$. 
Citation: Vidanapathirana AK, Thompson LC, Odom J, Holland NA, Sumner SJ, et al. (2014) Vascular Tissue Contractility Changes Following Late Gestational Exposure to Multi-Walled Carbon Nanotubes or their Dispersing Vehicle in Sprague Dawley Rats. J Nanomed Nanotechnol 5: 201. doi:10.4172/2157-7439.1000201

Page 11 of 15

\section{Changes in the fetal components following MWCNT exposure}

Changes in umbilical vein contractility: The reactivity of the umbilical vein (vessel from the placenta to the fetus) was assessed following both IT and IV administration. Stress generation during $\mathrm{K}^{+} \mathrm{PSS}$ and $1 \mu \mathrm{M}$ of thromboxane mimetic (U46619) stimulations were not significantly different in umbilical vessel segments between MWCNT exposed (by either exposure route) and naïve animals (Figure 6A-D). The umbilical vein segments did not respond to acetylcholine and the relaxation response to $1 \mu \mathrm{M}$ sodium nitroprusside with a stable U46619 pre-contraction was not different following MWCNT exposure (Figure 6E and F).

Changes in fetal and placental weight: Mean weights of pregnant dams at the time of sacrifice were not significantly different between treatment groups (mean \pm SEM): (S)-MWCNTs $298.2 \pm 12.0 \mathrm{~g}(n=6)$, $10 \%$ surfactant $291.0 \pm 10.8 \mathrm{~g}(n=6)$, (D)-MWCNTs $305.8 \pm 7.8 \mathrm{~g}(n=6)$, DPPC/RSA $333.4 \pm 24.9 \mathrm{~g}(n=6)$, and naïve $287.2 \pm 10.9 \mathrm{~g}(n=10)$. The mean and range of litter size were also not different between the exposure groups: (S)-MWCNTs 10.7 (8-13), 10\% surfactant 10.5 (1011), (D)-MWCNTs 9.8 (9-11), DPPC/RSA 10.5 (9-12) and naïve 10.6 (8-13). Mean weights of the fetuses are reported in Figure 7A and B, after grouping them according to gestational day (GD). The mean fetal weight was reduced at GD 19 following MWCNT and dispersion media exposure by both routes and was evident across all gestational days studied following intravenous exposure. Gross external morphological abnormalities were not seen in the fetuses. An increase in the mean placental weight was observed following MWCNT exposure by both routes on GD 18 (Figure 7C and D).

\section{Fetal serum cytokine analysis}

The cytokines levels in the fetal serum were not significantly changed following exposure to MWCNT or dispersion media by either route of administration and are reported in Table 2.

\section{Discussion}

Twenty hours post exposure to MWCNT by either intratracheal or intravenous administration resulted in a limited alteration in isolated blood vessel segments' responses to various pharmacological agents. The intratracheal instillation of $100 \mu \mathrm{g} / \mathrm{kg}$ of (S)-MWCNTs, was of note for we observed an increase in the contractile response to angiotensin II in the main uterine artery when compared to the response from the

\section{IT (S)-MWCNTs}

A

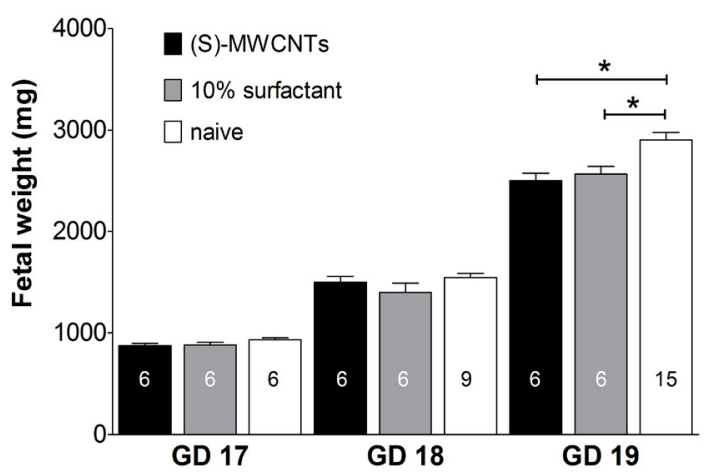

C

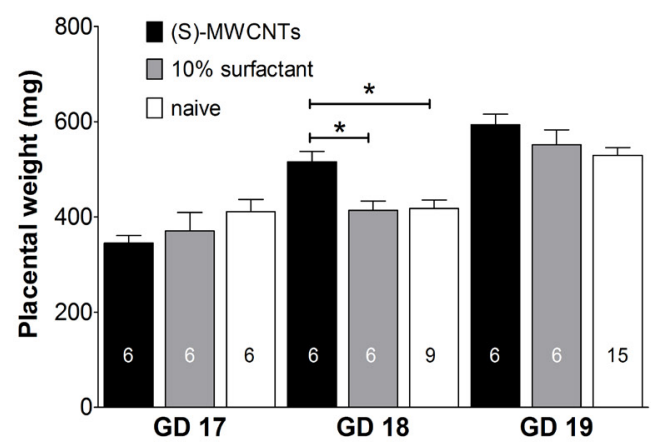

\section{IV (D)-MWCNTs}

B

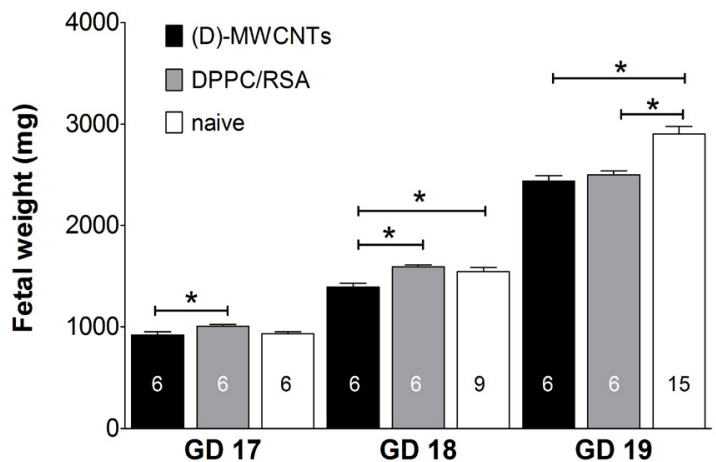

D

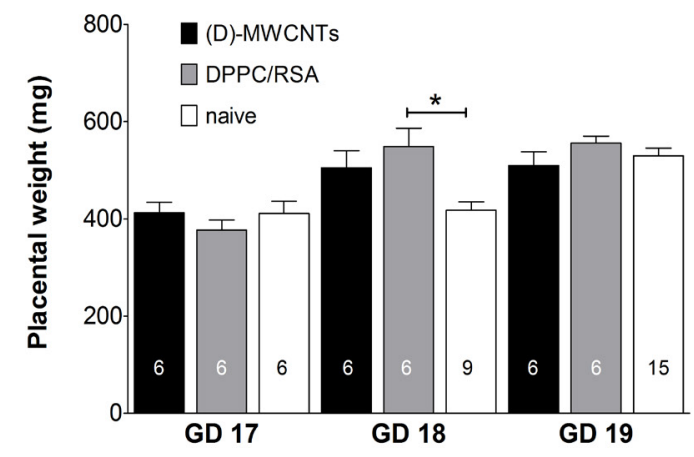

Figure 7: Changes in the fetal and placental weight following exposure to MWCNTs

Changes in fetal (A and B) and placental ( $\mathbf{C}$ and D) weight 24 hours post-exposure to intratracheal instillation (IT) of $100 \mu \mathrm{g} / \mathrm{kg}$ of (S)-MWCNTs or $10 \%$ surfactant (A and C) or intravenous administration (IV) of (D)-MWCNTs or DPPC/RSA ( B and D) in 17 - 19 days pregnant Sprague Dawley rats. Three pups/placentae were weighed from each dam included in the study and the number of pups/placentae are indicated within each bar. ${ }^{*}$ indicates $p<0.05$ when compared using one way ANOVA and Turkey post-hoc test. GD = day of gestation 
Citation: Vidanapathirana AK, Thompson LC, Odom J, Holland NA, Sumner SJ, et al. (2014) Vascular Tissue Contractility Changes Following Late Gestational Exposure to Multi-Walled Carbon Nanotubes or their Dispersing Vehicle in Spraque Dawley Rats. J Nanomed Nanotechnol 5 : 201. doi:10.4172/2157-7439.1000201

Page 12 of 15

\begin{tabular}{|c|c|c|c|c|c|}
\hline Cytokine & naive & $\begin{array}{c}\text { IT } \\
10 \% \text { surfactant }\end{array}$ & $\begin{array}{c}\text { IT } \\
\text { (S)-MWCNTs }\end{array}$ & $\begin{array}{c}\text { IV } \\
\text { DPPC/RSA }\end{array}$ & $\begin{array}{c}\text { IV } \\
\text { (D)-MWCNTs }\end{array}$ \\
\hline IL1ß $(\mathrm{pg} / \mathrm{ml})$ & $1455.0 \pm 372.5$ & $1597.0 \pm 310.3$ & $1657.0 \pm 699.4$ & $1932.0 \pm 861.7$ & $1500.0 \pm 375.9$ \\
\hline IL6 (pg/ml) & $75.7 \pm 16.8$ & $277.0 \pm 78.5^{\#}$ & $64.9 \pm 55.4$ & $120.4 \pm 86.5$ & $58.7 \pm 55.9$ \\
\hline IL10 (pg/ml) & $70.0 \pm 17.0$ & $76.0 \pm 13.5$ & $49.7 \pm 6.1$ & $117.2 \pm 56.9$ & $66.8 \pm 12.2$ \\
\hline INFY (pg/ml) & $283.3 \pm 42.5$ & $324.5 \pm 96.4$ & $278.7 \pm 30.6$ & $405.8 \pm 139.0$ & $355.9 \pm 139.0$ \\
\hline MCP1 (pg/ml) & $903.4 \pm 310.8$ & $986.7 \pm 137.7$ & $836.6 \pm 60.3$ & $991.2 \pm 184.6$ & $813.2 \pm 113.3$ \\
\hline VEGF $(p g / m l)$ & $469.5 \pm 83.0$ & $483.8 \pm 59.3$ & $457.2 \pm 52.2$ & $620.2 \pm 127.5$ & $512.1 \pm 47.0$ \\
\hline TNFa $(p g / m l)$ & $5.9 \pm 5.9$ & $3.3 \pm 3.3$ & $11.5 \pm 5.9$ & $6.7 \pm 4.2$ & $3.1 \pm 2.3$ \\
\hline
\end{tabular}

IT: intratracheal instillation and IV: intravenous administration, MWCNT: Multi-wall carbon nanotube, $10 \%$ surfactant: $10 \%$ surfactant in saline, (S)-MWCNTs: MWCNT suspended in $10 \%$ surfactant, DPPC/RSA: vehicle used for IV MWCNT delivery and (D)-MWCNTs: MWCNT suspended in DPPC/RSA

\# indicates $\mathrm{p}<0.05$ when compared to naïve.

Table 2: Cytokine levels in fetal serum 24 hours post-exposure to MWCNTs.

The fetal serum cytokines (a pooled sample from three fetuses/dam) were evaluated using Milliplex MAP Cytokine/Chemokine Panel and Immunoassay (EMD Millipore MA USA). These assays were run using Luminex 100/200 (Luminex, Austin, TX) and results reported using Luminex xPONENT ${ }^{\circledR}$ software versions 2.3/3.1. The mean and the SEM are reported for serum cytokines from fetuses from 17-19 days pregnant Sprague Dawley rats $(n=4-6)$.

non-pregnant state. This increase in of stress generation of the uterine artery following MWCNT exposure was confined to the late gestational stage. Minimal changes in the contractile responses due to MWCNT exposure were seen in vessel segments from the other vascular beds studied in both pregnant and non-pregnant state. The enhanced contractile responses were not associated with comparable changes in relaxation responses with Rho kinase inhibition, suggesting that mechanisms other than RhoA/Rho kinase may underlie alterations in contractile responses. To our knowledge, this is one of the first attempts to identify pregnancy related changes in the contractile responses of several vascular tissues following exposure to MWCNTs by different routes.

The physiochemical characteristics of the suspensions of the MWCNTs are important in understating any delivery characteristics. According to Henderson et al, the pulmonary responses are similar in response to particle exposure by either inhalation or instillation, provided similar lung burdens [37]. Intratracheal instillation has been suggested to deliver less well dispersed MWCNTs to the lung epithelium resulting in fewer adverse effects when compared to short term inhalational exposure [34,38]. On the other hand, instillation exposes the animal to an acute, higher concentration of nanoparticles compared to inhalational exposure over a long period [34], bypassing the nasal cavity. Accounting for these conditions, the results from our IT exposure might be used to speculate on the outcomes of long term inhalational exposure. Exposure levels have been identified in laboratory and industrial facilities [15] handling MWCNTs. Current proposed guidelines by the National Institute for Occupational Safety and Health (NIOSH) limits nanotube exposure to $7 \mu \mathrm{g} / \mathrm{m}^{3}[39]$ and a human occupational exposure of $5 \mathrm{mg} / \mathrm{m}^{3}$ during a 8-hour day and 40 hour work week equate to approximately $20 \mu \mathrm{g}$ of SWCNT aspiration in a mouse model [40]. A recent publication by Erdely et al. [41] identified a mean airborne mass concentration of $10.6 \mu \mathrm{g} / \mathrm{m}^{3} \mathrm{MWCNTs}$ across eight different facilities that handle carbon nanotubes in the United States, which was calculated to correspond with a human alveolar deposition of $4.07 \mu \mathrm{g} / \mathrm{day}$ [41]. In a study designed to mimic such conditions while weighing and moving dry materials, MWCNT were found to range from 4,514-123,403 particles/L of air [42]. Considering that average tidal volume in humans is $500 \mathrm{~mL}$ of air and average respiration rate is 12 breaths a minute (i.e. with a resting respiratory minute volume of 5 $\mathrm{L} / \mathrm{min}$ ), humans breathe approximately $360 \mathrm{~L}$ air/hour on average, this could result in a deposition of 1,625,040 - 44,425,080 MWCNT particles into the lungs in 1 hour. Based on calculations from flow-cytometry data (not shown), a $100 \mu \mathrm{g}$ MWCNT exposure mass translated to approximately 743,000 particles per rat. Employing these most recent occupational exposure values $\left(10.6 \mu \mathrm{g} / \mathrm{m}^{3}\right.$ [41]) it would require between 3-107 hours of constant occupational exposure to achieve a similar dosing used in our studies. Considering these conditions, and compared to other inhalational/instillation studies [13], $100 \mu \mathrm{g} / \mathrm{kg}$ dose used in the current study is a moderate - high dose. We choose to use an equivalent dose of MWCNTs in our IV exposure model to identify any effects of exposure to the same mass based dose of MWCNTs by two different routes. Future dose response studies including both low and high levels of exposure during pregnancy may be beneficial before applying these findings for regulatory purposes.

Previous studies with inhalational exposure to MWCNTs for 24-168 hours have identified a maximal impairment of endothelium dependent relaxation in coronary arterioles at 24 hours [11]. Therefore, the 24-hour post-exposure time point in this study should be conducive to identify changes in the contractile responses in extra-pulmonary vascular beds. Even during intravenous exposure, MWCNTs redistribute mainly to the lung and liver tissues [43] as pulmonary and hepatic circulations may be functioning as a filters during the first pass metabolism. The pulmonary responses to MWCNT deposition in such circumstances may be initiating the inflammatory cascade, contributing to changes in the contractile responses.

Several factors including the properties of MWCNT suspensions, route of exposure, pulmonary/systemic inflammatory response, pregnancy related physiological changes and sensitivity of the vascular bed may contribute to the differential contractile responses of vascular tissues that we have observed in this study. The reported zeta potentials of (S)-MWCNTs and (D)-MWCNTs suggest that both suspensions have a relatively good stability with minor agglomerate formation. The minor differences in the hydrodynamic size and zeta potential in different suspensions may not alone contribute significantly to modification of the vessel behavior via MWCNT exposure, as seen in different routes of exposure.

Previously reported distribution of MWCNTs following intravenous administration suggests that majority of the particles are distributed in the lungs following their first pass in circulation [23]. On the other hand, these particles are primarily distributed in the lungs following intratracheal instillation/ pulmonary exposure [44]. Considering these distribution patterns by both routes, we chose to study the immune mediated pulmonary responses by analyzing the cell counts in a broncoalveolar lavage. We report a pregnancy related increase in the BAL cell counts suggesting an inflammatory response, reported as higher percentages of macrophages with both dispersion media and (D)-MWCNTs and the increased neutrophils 
Citation: Vidanapathirana AK, Thompson LC, Odom J, Holland NA, Sumner SJ, et al. (2014) Vascular Tissue Contractility Changes Following Late Gestational Exposure to Multi-Walled Carbon Nanotubes or their Dispersing Vehicle in Sprague Dawley Rats. J Nanomed Nanotechnol 5: 201. doi:10.4172/2157-7439.1000201

with (S)-MWCNT exposure. Comparable changes in neutrophil and eosinophil counts were seen with pulmonary exposure to increasing doses of (S)-MWCNTs in a male mouse model [4]. These pulmonary responses following exposure to dispersion media or MWCNTs are also compatible with changes in the cytokine profiles, increased vascular tissue contractility and reduction in the fetal weight gain. The changes in the maternal serum cytokine levels reported in our study does not indicate any preferential immune response as IFN $\gamma$ (Th1), IL6 and IL10 (Th2) levels are not affected following exposure to MWCNTs by either route of administration. The increase in TNFa levels appears to be robustly influenced by both dispersant media (10\% surfactant and DPPC/RSA) rather than MWCNTs and may potentially induce a Th1 type response, which can be detrimental during pregnancy (36). This conclusion is also supported by the reduction in fetal weight seen with both (D)-MWCNTs and DPPC/RSA. An increase in IL1 $\beta$ level was seen with both $10 \%$ surfactant and DPPC/RSA suggesting an immunological response to both dispersion media, which was down-regulated by the addition of MWCNTs. Previous studies have reported both Th1 and Th2 type immune responses following acute exposure to MWCNTs with increased levels of: TNF $\alpha$, IL1 $\beta$, IL6, IL10, and MCP1 $(33,38)$ early after exposure and reported to wane over time (39), supporting the low levels we measured at 24 hours post-exposure.

The overall stress generation in segments of the main uterine artery, from the naive pregnant rats was lower compared to the response from naive non-pregnant rats, a response reflecting normal vasodilatory vascular behavior associated with pregnancy $[18,19]$. However, the uterine artery did present with an augmented response to Angiotensin II. Angiotensin II mediated responses are altered in the uterine vasculature during adverse pregnancy states such as pre-eclempsia where the AT1 receptor mediated constrictor function of angiotensin II predominates over the AT2 receptor mediated vasodilatory function $[45,46]$. The increased in contractility observed in the gestational uterine artery segments in our study could be mediated by alteration of either/both AT1 and AT2 receptor function following MWCNT exposure. Additionally, the calculated $\mathrm{EC}_{50}$ values for endothelin 1 were different in segments from all three vessels studied, suggesting an altered sensitivity to endothelin 1 or changes in endothelin receptor distribution with pregnancy. In contrast to the non-pregnant group, a significant increase in the contractile responses was evident only with the pregnant uterine artery segments, following (S)-MWCNT exposure. These observations suggest that pregnancy may render the uterine vasculature more susceptible to MWCNT exposure induced changes in contractility. Therefore, our observation of an increase in the contractile response or shifts in $\mathrm{EC}_{50}$ values following (S)-MWCNT exposure suggests there may be an adverse pregnancy outcome following pulmonary MWCNT exposure during pregnancy.

Compared to the uterine vasculature, the overall stress generation of mesenteric artery and thoracic aortic segments in response to contractile stimulation were not significantly different between naïve pregnant and non-pregnant animals. This relationship was not altered following MWCNT exposure by either route. The only difference in responses was observed at higher concentration of serotonin in the mesenteric artery, where we observed a higher stress generation/ lower relaxation response following (S)-MWCNT exposure that could be mediated by alteration in the serotonin receptor profiles following MWCNT exposure. We interpret the contrast in response of the vessels from the different vascular beds to be related to the limited extent of remodeling that occurs in the mesenteric artery and thoracic aorta with pregnancy and renders them less vulnerable to the influence of MWCNT exposure.
The alterations in contractile responses reported in this study (in response to angiotensin II and serotonin) are similar to the potentiation of stress generation reported with other cardiovascular pathologies, linked with elements of calcium sensitization and regulation of the contractions by RhoA/Rho kinase pathway $[47,48]$. As reported in Figure 5 and Supplementary Figure 4, there were only minor differences in the sensitivity to Rho kinase inhibition in all three vascular beds following exposure to MWCNTs or dispersion media by either route of exposure. Thus a response compatible with action of Rho kinase as being responsible for the augmented contractile responses was not evident with MWCNT exposure. Additionally, the lack of changes in Rho associated proteins and eNOS in rat aortic endothelial cells exposed to MWCNTs in vitro would suggest that this pathway is not mediating changes in the endothelial cell contribution to the augmented stress through regulation of eNOS as reviewed by Yao et al. [25] and Satoh et al. [48]. Thus in aggregate these data suggest that the rho kinase signaling was not a primary mechanism responsible for augmented stress generation observed following MWCNT exposure. Other mechanisms postulated to enhance force generation can include generation of reactive oxygen species [49], increased oxidative stress [50] and enhanced cyclooxygenase signaling [51]. SWCNTs have shown to increase oxidative stress and alter the mitochondrial signaling following intrapharyngeal instillation [52]. MWCNTs may also affect the cardiovascular functions by comparable mechanisms but have yet to be fully investigated.

Previous in vitro studies including proteomics analysis have shown that cellular functions and pathways comprising generalized gene transcription and protein translation are affected by direct exposure to MWCNTs [33,53]. Alternatively, the changes in the vascular system may be mediated through bronchial epithelial cell release of pro-inflammatory cytokines into circulation, such as IL6 and IL8 [6]. MWCNTs can also translocate following pulmonary exposure via instillation and reach the extra-pulmonary sites $[8,54]$, including the vasculature leading to a local inflammatory response. Our previous in vitro studies done with human aortic endothelial cells indicate increased expression of endothelial inflammatory markers following exposure to (S)-MWCNTs [33] and may support a mechanism for cytokine production which can influence vascular tissues.

When trying to understand the IT exposed MWCNT induced changes, it is important to recognize that $10 \%$ surfactant used as a vehicle for suspending the MWCNTs also induces a notable increase in stress generation in response to agonist stimulation compared the constrictive responses from naïve animal group. We suggest that (S)MWCNTs may have a combined effect of both MWCNTs and surfactant and this effect is clearly demonstrated in response to angiotensin II in the main uterine artery segments during pregnancy. However, synthetic lung surfactant based suspensions are established for studying pulmonary exposure effects of MWCNTs [55] and we chose to use the same for our study and were surprised to see such a vascular response effect. The responses seen with intravenous exposure to MWCNTs appear to be due to properties of the dispersant medium rather than due to nanotubes as DPPC/RSA significantly increases the baseline stress generation. The different media for the two routes of exposure were selected to simulate the biological media that area related to the exposure routes and were speculated to have no/minimal effects on vascular contractile responses. The dispersant medium is known to affect the cellular uptake of the nanoparticles [56] and presumed to impact overall cellular function. The dispersant media are known to contribute to the composition of protein or lipid corona associated with the nanoparticles in the biological systems $[57,58]$. It may be likely that 
Citation: Vidanapathirana AK, Thompson LC, Odom J, Holland NA, Sumner SJ, et al. (2014) Vascular Tissue Contractility Changes Following Late Gestational Exposure to Multi-Walled Carbon Nanotubes or their Dispersing Vehicle in Sprague Dawley Rats. J Nanomed Nanotechnol 5: 201. doi:10.4172/2157-7439.1000201

Page 14 of 15

the corona on these MWCNT is different enough to mask a significant MWCNT effect.

Neither MWCNTs nor dispersion medium induced significant changes in contractile responses of umbilical vein segments, suggesting that these exposures may only be affecting the maternal side of the circulation. However, detrimental effects were seen in the mean fetal weight following MWCNT exposure via both routes along with a significant contribution by the dispersion media alone. The IV exposure to (D)-MWCNTs appeared to be more effective at reducing the fetal growth earlier in gestational exposure window studied, whereas the weight reduction following IT exposure is mainly attributed to dispersion media. The placental transfer of the nanoparticles is affected by multiple factors including the particle size, dispersion medium, and the stage of the pregnancy [59] which could contribute to effects on fetal growth. Additionally, fetal microvessel dysfunction following exposure to engineered nanomaterials which was recently proposed by Stapleton et al. [11] may be a possible underlying explanation for our observations of reduced fetal weight despite the absence of augmented contractile responses in umbilical circulation. Stapleton et al. [11] used the fetal tail artery as a representative vessel from the fetal microcirculation and reported decreased responses in both endothelium dependent and independent relaxation [60]. Their findings suggests the applicability of the Barker Hypothesis (i.e. the relation between retarded growth in early life and risk of adult disease is due to long term effects on physiology and metabolism imposed by an adverse environment during critical periods of development) to explain the changes observed in the fetus following maternal nanoparticle exposure [60,61]. This hypothesis may also hold true for our MWCNT exposure scenario, suggesting that the differences in the fetal weight gain may be a reflection of limited blood supply due to increased contraction observed in the uterine vascular segments.

\section{Conclusions}

In conclusion, the observations in this study suggest that vascular contractility may change following MWCNT exposure depending on multiple factors, including life stage (pregnant or non-pregnant), route of exposure, MWCNT dispersion media and the target vascular bed. Multiple agonist-mediated responses are differentially affected between the pregnant and non-pregnant stages with a significant increase in the stress generation of the uterine artery in response to angiotensin II confined to the pregnant stage. These agonists alter the contractile mechanism through various signaling cascades and we assessed the contribution RhoA/Rho kinase pathway in mediating these responses. We were unable to demonstrate that the RhoA/Rho kinase signaling cascade was significantly altered in response to MWCNT exposure and could not account for the augmented contractile responses, suggesting that other pro-constrictor mechanisms are likely to be involved. Our comparisons with naïve rats revealed a significant influence of the dispersion media on vascular tissue contractility and fetal weight gain, suggesting MWCNT exposure in isolation has no/minimal effects under the exposure scenarios applied in this study.

\section{Acknowledgements}

We like to thank Dr. Walter Kline of ONY Inc. for the generous gift of Infasurf surfactant, Drs. Benjamin Harrison and Richard Czerw of Nanotech Labs Inc. for providing the multi-walled carbon nanotubes for this study. We would also like to thank Drs. Pu-Chun Ke and Apparao M. Rao for previous work on characterization of the dry powder form of the multi-walled carbon nanotubes and to Josh E. Pitzer for assistance in rat aortic endothelial cell culture and PCR. This project was funded by the National Institute of Environmental Health Sciences grant U19 ES019525 and an AHA Mid-Atlantic Affiliate pre-doctoral fellowship to AKV.

\section{References}

1. Harrison BS, Atala A (2007) Carbon nanotube applications for tissue engineering. Biomaterials 28: 344-353.

2. Pescatori M, Bedognetti D, Venturelli E, Ménard-Moyon C, Bernardini C, et al. (2013) Functionalized carbon nanotubes as immunomodulator systems. Biomaterials 34: 4395-4403.

3. Osmond-McLeod MJ, Poland CA, Murphy F, Waddington L, Morris $\mathrm{H}$, et al (2011) Durability and inflammogenic impact of carbon nanotubes compared with asbestos fibres. Part Fibre Toxicol 8: 15

4. Wang X, Katwa P, Podila R, Chen P, Ke PC, et al. (2011) Multi-walled carbon nanotube instillation impairs pulmonary function in C57BL/6 mice. Part Fibre Toxicol 8: 24 .

5. Murphy FA Schinwald A, Poland CA, Donaldson K (2012) The mechanism of pleural inflammation by long carbon nanotubes: interaction of long fibres with macrophages stimulates them to amplify pro-inflammatory responses in mesothelial cells. Part Fibre toxicol 9: 8.

6. Hirano S, Fujitani Y, Furuyama A, Kanno S (2010) Uptake and cytotoxic effects of multi-walled carbon nanotubes in human bronchial epithelial cells. Toxico Appl Pharmacol 249: 8-15.

7. Guo YY, Zhang J, Zheng YF, Yang J, Zhu XQ (2011) Cytotoxic and genotoxic effects of multi-wall carbon nanotubes on human umbilical vein endothelial cells in vitro. Mutat Res 721: 184-191.

8. Aiso S, Kubota H, Umeda Y, Kasai T, Takaya M, et al. (2011) Translocation of intratracheally instilled multiwall carbon nanotubes to lung-associated lymph nodes in rats. Ind Health 49: 215-220.

9. Porter DW, Hubbs AF, Chen BT, McKinney W, Mercer RR, et al. (2013) Acute pulmonary dose-responses to inhaled multi-walled carbon nanotubes. Nanotoxicology 7: 1179-1194.

10. Oberdörster G, Sharp Z, Atudorei V, Elder A, Gelein R, et al. (2002) Extrapulmonary translocation of ultrafine carbon particles following whole-body inhalation exposure of rats. J Toxicol Environ Health A 65: 1531-1543.

11. Stapleton PA, Minarchick VC, Cumpston AM, McKinney W, Chen BT, et al (2012) Impairment of coronary arteriolar endothelium-dependent dilation after multi-walled carbon nanotube inhalation: a time-course study. Int J Mol Sci 13 13781-13803.

12. Thompson LC, Frasier CR, Sloan RC, Mann EE, Harrison BS, et al. (2014) Pulmonary instillation of multi-walled carbon nanotubes promotes coronary vasoconstriction and exacerbates injury in isolated hearts. Nanotoxicology 8 : $38-49$.

13. Castranova V, Schulte PA, Zumwalde RD (2013) Occupational nanosafety considerations for carbon nanotubes and carbon nanofibers. Acc Chem Res 46: 642-649.

14. Han JH, Lee EJ, Lee JH, So KP, Lee YH, et al. (2008) Monitoring multiwalled carbon nanotube exposure in carbon nanotube research facility. Inhal Toxicol 20: 741-749.

15. Takaya $M$, Ono-Ogasawara $M$, Shinohara $\mathrm{Y}$, Kubota $\mathrm{H}$, Tsuruoka $\mathrm{S}$, et al. (2012) Evaluation of exposure risk in the weaving process of MWCNT-coated yarn with real-time particle concentration measurements and characterization of dust particles. Ind Health 50: 147-155.

16. Wu H, Liu G, Zhuang Y, Wu D, Zhang H, et al. (2011) The behavior after intravenous injection in mice of multiwalled carbon nanotube / Fe3O4 hybrid MRI contrast agents. Biomaterials 32: 4867-4876.

17. Lim JH, Kim SH, Lee IC, Moon C, Kim SH, et al. (2011) Evaluation of Materna Toxicity in Rats Exposed to Multi-Wall Carbon Nanotubes during Pregnancy. Environ Health Toxicol 26: e2011006.

18. Osol G, Mandala M (2009) Maternal uterine vascular remodeling during pregnancy. Physiology (Bethesda) 24: 58-71.

19. Osol G, Barron C, Gokina N, Mandala M (2009) Inhibition of nitric oxide synthases abrogates pregnancy-induced uterine vascular expansive remodeling. J Vasc Res 46: 478-486.

20. Jain S, Thakare VS, Das M, Godugu C, Jain AK, et al. (2011) Toxicity of multiwalled carbon nanotubes with end defects critically depends on their functionalization density. Chem Res Toxicol 24: 2028-2039.

21. Al Faraj A FF, Luciani N, Lacroix G, Levy M, Crémillieux $Y$, et al. (2011) In vivo 
Citation: Vidanapathirana AK, Thompson LC, Odom J, Holland NA, Sumner SJ, et al. (2014) Vascular Tissue Contractility Changes Following Late Gestational Exposure to Multi-Walled Carbon Nanotubes or their Dispersing Vehicle in Sprague Dawley Rats. J Nanomed Nanotechnol 5 : 201. doi:10.4172/2157-7439.1000201

biodistribution and biological impact of injected carbon nanotubes using magnetic resonance techniques. International Journal of Nanomedicine 6: 351-361.

22. Singh R, Pantarotto D, Lacerda L, Pastorin G, Klumpp C, et al. (2006) Tissue biodistribution and blood clearance rates of intravenously administered carbon nanotube radiotracers. Proc Natl Acad Sci U S A 103: 3357-3362.

23. Lacerda L, Ali-Boucetta H, Herrero MA, Pastorin G, Bianco A, et al. (2008) Tissue histology and physiology following intravenous administration of different types of functionalized multiwalled carbon nanotubes. Nanomedicine (London, England) 3: 149-161.

24. Fukata Y, Amano M, Kaibuchi K (2001) Rho-Rho-kinase pathway in smooth muscle contraction and cytoskeletal reorganization of non-muscle cells. Trends Pharmacol Sci 22: 32-39.

25. Yao L, Romero MJ, Toque HA, Yang G, Caldwell RB, et al. (2010) The role of RhoA/Rho kinase pathway in endothelial dysfunction. J Cardiovasc Dis Res 1: $165-170$.

26. Li H, Peng W, Jian W, Li Y, Li Q, et al. (2012) ROCK inhibitor fasudil attenuated high glucose-induced MCP-1 and VCAM-1 expression and monocyteendothelial cell adhesion. Cardiovasc Diabetol 11:65.

27. Sun Q, Yue P, Ying Z, Cardounel AJ, Brook RD, et al. (2008) Air pollution exposure potentiates hypertension through reactive oxygen species-mediated activation of Rho/ROCK. Arterioscler Thromb Vasc Biol 28: 1760-1766.

28. Bihari P, Vippola M, Schultes S, Praetner M, Khandoga AG, et al. (2008) Optimized dispersion of nanoparticles for biological in vitro and in vivo studies. Part Fibre Toxicol 5: 14

29. Wang X, Podila R, Shannahan JH, Rao AM, Brown JM (2013) Intravenously delivered graphene nanosheets and multiwalled carbon nanotubes induce sitespecific Th2 inflammatory responses via the IL-33/ST2 axis. Int J Nanomedicine 8: $1733-1748$.

30. Dalle Lucca JJ, Adeagbo AS, Alsip NL (2000) Oestrous cycle and pregnancy alter the reactivity of the rat uterine vasculature. Hum Reprod 15: 2496-2503.

31. Dalle Lucca JJ, Adeagbo AS, Alsip NL (2000) Influence of oestrous cycle and pregnancy on the reactivity of the rat mesenteric vascular bed. Hum Reprod 15: $961-968$

32. Osol G, Moore LG (2014) Maternal uterine vascular remodeling during pregnancy. Microcirculation 21: 38-47

33. Vidanapathirana AK, Lai X, Hilderbrand SC, Pitzer JE, Podila R, et al. (2012) Multi-walled carbon nanotube directed gene and protein expression in cultured human aortic endothelial cells is influenced by suspension medium. Toxicology 302: 114-122.

34. Morimoto Y, Hirohashi M, Ogami A, Oyabu T, Myojo T, et al. (2012) Pulmonary toxicity of well-dispersed multi-wall carbon nanotubes following inhalation and intratracheal instillation. Nanotoxicology 6: 587-599.

35. Kusinski LC, Baker PN, Sibley CP, Wareing M (2009) In vitro assessment of mouse uterine and fetoplacental vascular function. Reprod Sci 16: 740-748.

36. Ludbrook J (1994) Repeated measurements and multiple comparisons in cardiovascular research. Cardiovasc Res 28: 303-311.

37. Henderson RF, Driscoll KE, Harkema JR, Lindenschmidt RC, Chang IY, et al (1995) A comparison of the inflammatory response of the lung to inhaled versus instilled particles in F344 rats. Fundam Appl Toxicol 24: 183-197.

38. Shvedova AA, Kisin E, Murray AR, Johnson VJ, Gorelik O, et al. (2008) Inhalation vs. aspiration of single-walled carbon nanotubes in C57BL/6 mice: inflammation, fibrosis, oxidative stress, and mutagenesis. Am J Physiol Lung Cell Mol Physiol 295: L552-565.

39. Dahm MM, Evans DE, Schubauer-Berigan MK, Birch ME, Fernback JE (2012) Occupational exposure assessment in carbon nanotube and nanofiber primary and secondary manufacturers. Ann Occup Hyg 56: 542-556.

40. Shvedova AA, Kisin ER, Mercer R, Murray AR, Johnson VJ, et al. (2005) Unusual inflammatory and fibrogenic pulmonary responses to single-walled carbon nanotubes in mice. Am J Physiol Lung Cell Mol Physiol 289: L698-708.

41. Erdely A, Dahm M, Chen BT, Zeidler-Erdely PC, Fernback JE, et al. (2013) Carbon nanotube dosimetry: from workplace exposure assessment to inhalation toxicology. Part Fibre Toxicol 10: 53

42. Johnson DR, Methner MM, Kennedy AJ, Steevens JA (2010) Potentia for occupational exposure to engineered carbon-based nanomaterials in environmental laboratory studies. Environ Health Perspect 118: 49-54.
43. Wei Q, Zhan L, Juanjuan B, Jing W, Jianjun W, et al. (2012) Biodistribution of co-exposure to multi-walled carbon nanotubes and nanodiamonds in mice. Nanoscale Res Lett 7: 473.

44. Kim JE, Lim HT, Minai-Tehrani A, Kwon JT, Shin JY, et al. (2010) Toxicity and clearance of intratracheally administered multiwalled carbon nanotubes from murine lung. J Toxicol Environ Health A 73: 1530-1543.

45. Hannan RE, Davis EA, Widdop RE (2003) Functional role of angiotensin I AT2 receptor in modulation of AT1 receptor-mediated contraction in rat uterine artery: involvement of bradykinin and nitric oxide. Br J Pharmacol 140: 987-995.

46. LaMarca B, Wallace K, Granger J (2011) Role of angiotensin II type I receptor agonistic autoantibodies (AT1-AA) in preeclampsia. Curr Opin Pharmacol 11 175-179.

47. Christ G, Wingard C (2005) Calcium sensitization as a pharmacological target in vascular smooth-muscle regulation. Curr Opin Investig Drugs 6: 920-933.

48. Satoh K, Fukumoto Y, Shimokawa H (2011) Rho-kinase: important new therapeutic target in cardiovascular diseases. Am J Physiol Heart Circ Physio 301: H287-296.

49. Pacurari M, Qian Y, Fu W, Schwegler-Berry D, Ding M, et al. (2012) Cell permeability, migration, and reactive oxygen species induced by multiwalled carbon nanotubes in human microvascular endothelial cells. J Toxicol Environ Health A 75: 129-147.

50. Shvedova AA, Pietroiusti A, Fadeel B, Kagan VE (2012) Mechanisms of carbon nanotube-induced toxicity: focus on oxidative stress. Toxicol Appl Pharmacol 261: 121-133.

51. Sayers BC, Taylor AJ, Glista-Baker EE, Shipley-Phillips JK, Dackor RT, et al. (2013) Role of cyclooxygenase-2 in exacerbation of allergen-induced airway remodeling by multiwalled carbon nanotubes. Am J Respir Cell Mol Biol 49: $525-535$.

52. Li Z, Hulderman T, Salmen R, Chapman R, Leonard SS, et al. (2007) Cardiovascular effects of pulmonary exposure to single-wall carbon nanotubes. Environ Health Perspect 115: 377-382.

53. Haniu H, Matsuda Y, Takeuchi K, Kim YA, Hayashi T, et al. (2010) Proteomicsbased safety evaluation of multi-walled carbon nanotubes. Toxicol App Pharmacol 242: 256-262

54. Reddy AR, Krishna DR, Reddy YN, Himabindu V (2010) Translocation and extra pulmonary toxicities of multi wall carbon nanotubes in rats. Toxicol Mech Methods 20: 267-272.

55. Ronzani C, Spiegelhalter C, Vonesch JL, Lebeau L, Pons F (2012) Lung deposition and toxicological responses evoked by multi-walled carbon nanotubes dispersed in a synthetic lung surfactant in the mouse. Arch Toxico 86: $137-149$

56. Haniu H, Saito N, Matsuda Y, Kim YA, Park KC, et al. (2011) Effect of dispersants of multi-walled carbon nanotubes on cellular uptake and biological responses. Int J Nanomedicine 6: 3295-3307.

57. Lundqvist M, Stigler J, Cedervall T, Berggård T, Flanagan MB, et al. (2011) The evolution of the protein corona around nanoparticles: a test study. ACS Nano 5: 7503-7509.

58. Wang X, Xia T, Ntim SA, Ji Z, Lin S, et al. (2011) Dispersal state of multiwalled carbon nanotubes elicits profibrogenic cellular responses that correlate with fibrogenesis biomarkers and fibrosis in the murine lung. ACS Nano 5: 9772-9787.

59. Kulvietis V, Zalgeviciene V, Didziapetriene J, Rotomskis R (2011) Transport of nanoparticles through the placental barrier. Tohoku J Exp Med 225: 225-234

60. Stapleton PA, Minarchick VC, Yi J, Engels K, McBride CR, et al. (2013) Materna engineered nanomaterial exposure and fetal microvascular function: does the Barker hypothesis apply? American journal of obstetrics and gynecology 209 227.e1-11.

61. Barker DJ, Martyn CN (1992) The maternal and fetal origins of cardiovascular disease. J Epidemiol Community Health 46: 8-11. 